\title{
Changes in Normalized Difference Vegetation Index in the Orinoco and Amazon River Basins: Links to Tropical Atlantic Surface Temperatures ${ }^{\mathscr{O}}$
}

\author{
PAOLA A. ARIAS \\ Grupo de Ingeniería y Gestión Ambiental, Escuela Ambiental, Facultad de Ingeniería, Universidad de Antioquia, \\ Medellín, Colombia \\ J. Alejandro MartíneZ \\ Escuela Ambiental, Facultad de Ingeniería, Universidad de Antioquia, Medellín, Colombia \\ JuAN DAVID MEJÍA AND MARÍA JosÉ PAZOS \\ Grupo de Ingeniería y Gestión Ambiental, Escuela Ambiental, Facultad de Ingeniería, Universidad de Antioquia, \\ Medellín, Colombia \\ JHAN CARLO ESPINOZA AND SLY WONGCHUIG-CORREA \\ Institut des Géosciences de l'Environnement, Université Grenoble Alpes, IRD, CNRS, Grenoble, France
}

(Manuscript received 17 September 2019, in final form 14 July 2020)

\begin{abstract}
We analyze the observed relationship between sea surface temperatures (SSTs) over the Atlantic Ocean and the normalized difference vegetation index (NDVI) in the Orinoco and Amazon basins. Monthly correlations between anomalies of NDVI and SSTs are computed for different regions of the Atlantic Ocean. We also use a mixture of observations and reanalysis products to analyze lagged correlations. Our results show that during August-September (i.e., the dry-to-wet transition season), changes in NDVI in the central Amazon and the so-called Arc of Deforestation are associated with precedent changes in the SSTs of the tropical North Atlantic (TNA) and the Caribbean (CABN) during March-June. Anomalous warming of the CABN and TNA generates changes in surface winds and atmospheric moisture transport in the region, decreasing precipitation, with consequent decreases of soil moisture, moisture recycling, and NDVI. An increase in TNA and CABN SSTs during March-June is also associated with an increase of NDVI over the northern Orinoco during June (i.e., the wet season). Unlike in the southern Amazon, precipitation and soil moisture in the Orinoco basin do not exhibit significant changes associated with SSTs. By contrast, atmospheric moisture recycling and transport increase with warmer SSTs in the TNA. Therefore, for the Orinoco, the link between SSTs and NDVI appears to be related not to changes in precipitation but to changes in moisture recycling. However, the causality between these changes needs to be further explored. These findings highlight the contrasting responses of the Amazon and Orinoco basins to Atlantic temperatures and the dominant role of atmospheric moisture transport linking these responses.
\end{abstract}

KEYWORDS: Atmosphere-land interaction; Atmospheric circulation; Dynamics; Transport; Vegetationatmosphere interactions

Supplemental information related to this paper is available at the Journals Online website: https://doi.org/10.1175/JCLI-D-190696.s1.

Corresponding author: Paola A. Arias, paola.arias@udea.edu.co

\section{Introduction}

The hydrological cycle in northern South America strongly depends on the atmospheric moisture provided not only by the adjacent oceans (mainly the tropical Atlantic) but also by continental sources like the Amazon 
and Orinoco River basins (Arias et al. 2015b; Hoyos et al. 2019; Nieto et al. 2008; Sakamoto et al. 2011). The Amazon rain forest influences climate dynamics and the carbon cycle at regional and global scales (Nobre et al. 2009; Zhao et al. 2017). The entire basin behaves like an atmospheric moisture reservoir, while the northern region may act as a net moisture source when extreme droughts occur (Marengo 2005). Thus, changes in the Amazon biosphere may affect its roles in climate regulation and biodiversity conservation, and interfere in its function as a source of atmospheric humidity for other regions in South America (Boers et al. 2017). For instance, the southern Amazon basin is an important source of water vapor for southern Brazil, northern Argentina, and the Paraná-La Plata River basins (Martinez and Dominguez 2014), which is transported by the South American low-level jet (SALLJ) that develops on the eastern slope of the Andes (Jones 2019; Marengo 2006; Montini et al. 2019; Vera et al. 2006b). In addition, the southern Amazon provides water vapor to the tropical Andes (Ampuero et al. 2020; Espinoza et al. 2020; RuizVásquez et al. 2020). Regarding annual precipitation, the northern Amazon is mainly affected by the meridional migration of the intertropical convergence zone (ITCZ) whereas the southern Amazon is influenced by the South American monsoon system (SAMS) and the South Atlantic convergence zone (SACZ) (Vera et al. 2006a). Recent studies have identified an intensification of extreme hydrological events in the Amazon basin (Marengo and Espinoza 2016) with heightened frequencies of extreme droughts (e.g., in 2005, 2010, and 2015-16) and floods (e.g., in 2006, 2009, 2012, and 2014). In addition, a strengthening of the hydrological cycle in the Amazon basin has been reported since the late 1990s due to a strengthening of the Walker and Hadley circulations and the warming of the tropical Atlantic Ocean (Barichivich et al. 2018).

The atmospheric moisture available in a specific region depends on advection from remote regions as well as on local processes related to precipitation recycling (Burde and Zangvil 2001). The latter largely depends on local evapotranspiration. The recycling rate is defined as the ratio between the amount of precipitation that originates locally and the amount of moisture for precipitation that is imported into the region by advective processes. In the Amazon basin, atmospheric moisture recycling varies substantially, from low recycling rates during the austral summer and autumn (rainy season in central and southern parts of the basin) to higher recycling rates during the austral winter and spring (dry season in southern Amazonia), when large-scale atmospheric moisture convergence decreases $(\mathrm{Fu}$ and $\mathrm{Li}$ 2004; Marengo 2006; Wright et al. 2017). During drought years, the stability of the water cycle in the Amazon basin is altered as soils lose the abundant levels of moisture collected during neutral years (Frappart et al. 2012; Hodnett et al. 1996). This hinders the water extraction from the subsoil layers by plants through deep root systems and the hydraulic redistribution that occurs in the surface soil layer during nighttime, which is an important process to sustain vegetation and evapotranspiration during the dry season (da Rocha et al. 2004). Hence, the recycling rate takes its largest values during the dry season since it is the main source of water vapor to recharge the atmosphere (Marengo 2006; Wright et al. 2017), coinciding with the dry phase of the SAMS (Vera et al. 2006a). Therefore, vegetation is an important local element for the generation of moisture over the Amazon, evidenced by the high rates of recycled precipitation in this region, with reanalysis-based estimates ranging between $27 \%$ and 33\% (Costa and Foley 1999; Eltahir and Bras 1996). Recycling rates reach even larger values over the western Amazon and the Amazon-Andes transition region (Zemp et al. 2017), where around 50\% of total annual rainfall traces back to transpiration by trees in the Amazon basin (Staal et al. 2018). In this sense, the current rates of deforestation observed in Amazonia (Aguiar et al. 2016; Davidson et al. 2012) could ultimately have consequences on the availability of water resources in this basin (Boers et al. 2017; Molina et al. 2019; RuizVásquez et al. 2020; Spracklen and Garcia-Carreras 2015; Swann et al. 2015).

Observational and modeling studies demonstrate the fundamental role of the Amazon basin in the transport and recycling of atmospheric moisture (Agudelo et al. 2018; Boers et al. 2017; Molina et al. 2019; Ruiz-Vásquez et al. 2020). On the other hand, previous studies indicate that the annual cycles of vegetation-related variables are negatively correlated with precipitation over tropical forest areas. This suggests that vegetation photosynthetic activity is highest during the dry season and that the wet season inhibits the greening of vegetation (Huete et al. 2006; Morton et al. 2014; Restrepo-Coupe et al. 2013; Saleska et al. 2016; Wagner et al. 2017). Tropical forests respond to variations in precipitation with a delay between 0 and 2 months (Zhao et al. 2017). In turn, precipitation over tropical regions is partially modulated by variations in sea surface temperatures (SSTs). Studies suggest that an increase in tropical SSTs and the associated shifts of the ITCZ could induce drier conditions over the major tropical forests, including extreme droughts in the southern Amazon basin (Marengo and Espinoza 2016). For instance, the forcings induced by warming of the tropical Atlantic Ocean and variability associated with El Niño-Southern Oscillation (ENSO) 
could generate atmospheric circulation anomalies that favor the occurrence of extreme droughts, like those observed in the Amazon basin during 2005 and 2010 (Coelho et al. 2012; Erfanian et al. 2017; Espinoza et al. 2011; Lewis et al. 2011; Marengo et al. 2008, 2011; Marengo and Espinoza 2016; Panisset et al. 2018; Zeng et al. 2008). These dry anomalies could result in forest canopy degradation, increased tree mortality, decreased availability of water resources at local and regional scales, and altered regional climate and carbon dynamics (Espinoza et al. 2016; Fernandes et al. 2011; Hilker et al. 2014; Maeda et al. 2015).

By contrast, savanna ecosystems are characterized by a relatively smaller amount of rainfall and a positive correlation between vegetation greenness and rainfall, indicating that photosynthesis is enhanced during the wet season (Hilker et al. 2014; Zhao et al. 2017). This type of vegetation exhibits a delay in its response to rainfall variations of about 3 to 4 months. This greater delay means that savanna vegetation takes longer to respond to rainfall anomalies than tropical forests; hence vegetation activity depends on precipitation that occurred in previous seasons (Zhao et al. 2017). The Orinoco River basin is characterized by the predominance of savanna forests. The annual distribution of rainfall in this region is mainly influenced by the position of the ITCZ (Poveda et al. 2006; Poveda and Mesa 1997). The Orinoco basin experiences its dry season between November and April and its wet season between May and October (Poveda et al. 2006). During the Orinoco dry season (austral summer), the ITCZ experiences a southward migration, allowing the northeasterly trade winds to intensify over Venezuela. This southward migration is related to the establishment of a strong pressure gradient between the North Atlantic subtropical high (NASH) and the Amazon, allowing the trade winds to intrude from northeastern to southwestern Venezuela. This feature is associated with the channeling effect of the topographic barrier between the Coast Cordillera and the Guianas Shield (Vernekar et al. 2003), in a circulation pattern known as the Los Llanos low-level jet (LLJ), which influences the precipitation regime in the Orinoco River basin (Jiménez-Sánchez et al. 2019; Torrealba and Amador 2010). Radiosonde measurements of the Los Llanos LLJ show peak of wind speeds from late January to March, which corresponds to the dry season in the region. The weakest wind speeds are observed in July and August, which corresponds to the rainy season (Jiménez-Sánchez et al. 2019; Torrealba and Amador 2010).

Multiple studies have identified relationships between precipitation over the Venezuelan Llanos region and interannual and seasonal modes of SST variability in the adjacent oceans (i.e., the Caribbean Sea and the tropical North and South Atlantic). Such studies indicate negative correlations between Venezuelan rainfall and wind anomalies over the Caribbean, suggesting that the dominant mechanisms that produce precipitation over this area could be modulated by variations in these winds (JiménezSánchez et al. 2019; Torrealba and Amador 2010). Furthermore, the tropical Atlantic is the main source of water vapor to the Orinoco region, which is transported by the trade winds (Labat et al. 2012; Nieto et al. 2008).

This study aims to contribute to current understanding regarding the response of vegetation in two fundamental hydrological basins of South America to forcing associated with tropical SST variability. We focus on identifying the relationship between vegetation conditions in the Orinoco and Amazon basins and the variability of SSTs in the Atlantic Ocean. We analyze monthly correlations between anomalies of normalized difference vegetation index (NDVI) in these basins and SST anomalies in different regions of the Atlantic Ocean. We also analyze variables associated with soil conditions (volumetric soil moisture and terrestrial water storage) and atmospheric circulation in the region (surface winds, precipitation, and precipitable water) during two anomalous warm years in the Atlantic Ocean: 2005 and 2010. These years are considered since extreme droughts over the Amazon were observed during both years (Coelho et al. 2012; Erfanian et al. 2017; Espinoza et al. 2011; Lewis et al. 2011; Marengo et al. 2008, 2011; Marengo and Espinoza 2016; Panisset et al. 2018; Zeng et al. 2008). Also, 2010 was one of the strongest wet seasons recorded over northern South America in decades (Arias et al. 2015b; Hoyos et al. 2013; Trenberth and Fasullo 2012).

\section{Data and methodology}

\section{a. Data}

We use monthly data of SST, NDVI, precipitation, volumetric soil moisture (VSM), terrestrial water storage (TWS), and horizontal winds at $850 \mathrm{hPa}$. SST is obtained from the Optimum Interpolation version 2 (OI V2) database of the National Oceanic and Atmospheric Administration (NOAA) (Reynolds et al. 2002), during the period between December 1981 and August 2018, with a spatial resolution of $1^{\circ} \times 1^{\circ}$. This dataset is available at https://www.esrl.noaa.gov/ psd/data/gridded/data.noaa.oisst.v2.html.

The NDVI allows for monitoring seasonal, interannual, and long-term variations of the structural, phenological, and biophysical parameters of vegetation (Huete et al. 2006). Therefore, we use NDVI records from the NOAA Advanced Very High Resolution Radiometer (AVHRR), obtained in the framework of the Global Monitoring Inventory and Modeling System (GIMMS) project. The latest version of the GIMMS NDVI monthly data is available from July 1981 through December 2015, with a spatial 


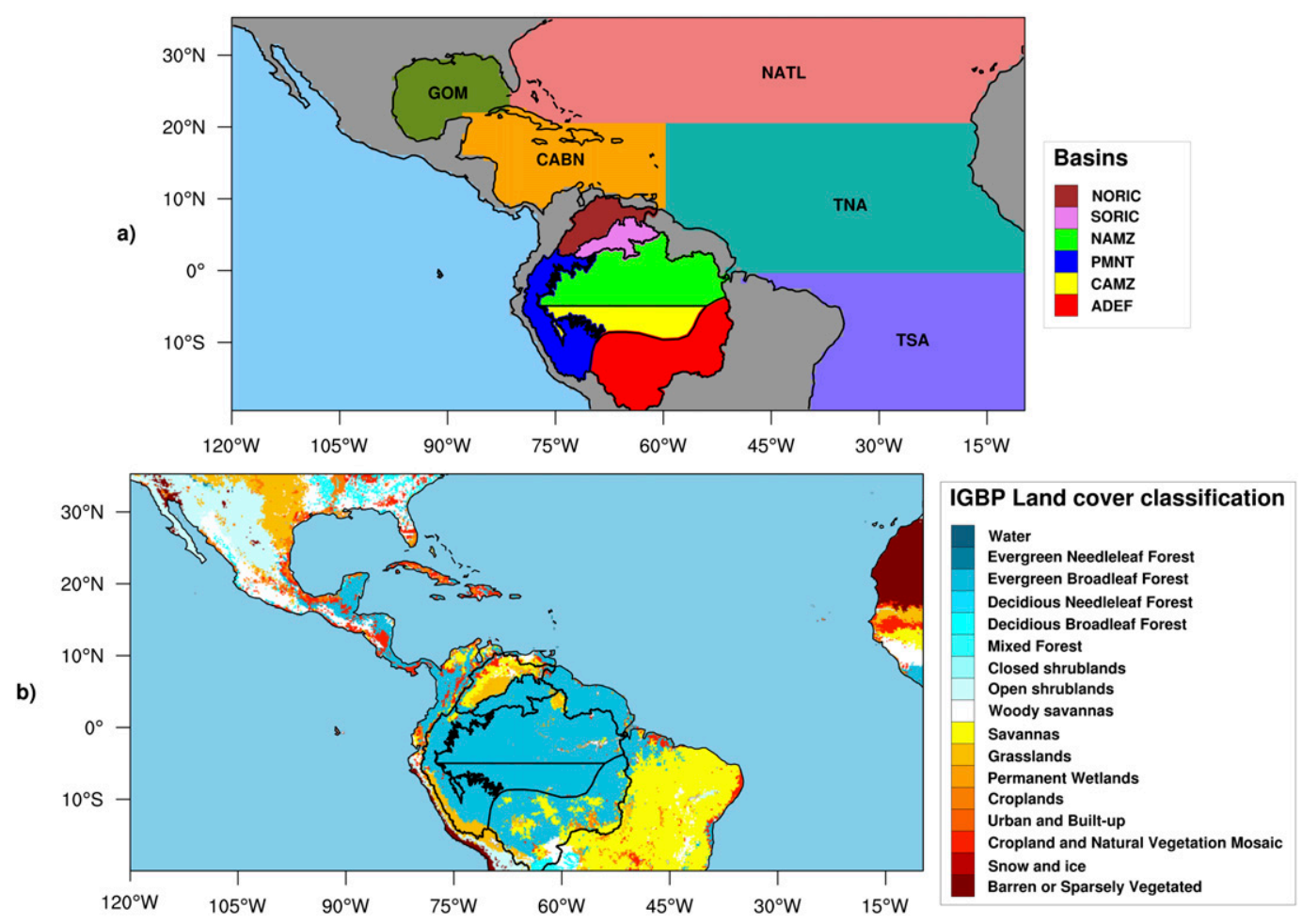

FIG. 1. (a) Subregions of the Atlantic Ocean considered for estimating SST anomalies: Gulf of Mexico (GOM), northern Atlantic (NATL), Caribbean Sea (CABN), tropical North Atlantic (TNA), and tropical South Atlantic (TSA). Color shades in the continents show the regions considered for analyzing NDVI responses to SSTs: the northern (NORIC) and southern Orinoco (SORIC) river basin, northern (NAMZ) and central (CAMZ) Amazon basin, Arc of Deforestation (ADEF), and Andes-Amazon piedmont/foothills (PMNT). (b) Current land-cover classification from the International Geosphere-Biosphere Programme (IGBP; available at https:/climatedataguide.ucar.edu/ climate-data/ceres-igbp-land-classification) (shading). Contours indicate continental regions defined in (a). To estimate water vapor transport with DRM, we consider the oceanic regions shown in (a). Also, we consider two continental regions corresponding to the Amazon River basin: The first region, NoAmaz, includes NAMZ and the PMNT region north of $5^{\circ} \mathrm{S}$; the second region, SoAmaz, includes CAMZ, ADEF, and the PMNT region south of $5^{\circ} \mathrm{S}$. Finally, we consider one continental region corresponding to the Orinoco basin (ORIC) which includes both NORIC and SORIC regions.

resolution of $0.083^{\circ}$ (available at https://climatedataguide.ucar.edu/ climate-data/ndvi-normalized-difference-vegetationindex-3rd-generation-nasagfsc-gimms). The AVHRR detectors allow the measurement of radiation intensity and the quantification of the photosynthetic capacity of vegetation in pixels of Earth's surface (NASA Earth Observatory; https://earthobservatory.nasa.gov/features/ MeasuringVegetation/measuring_vegetation_2.php). However, AVHRR measurements are limited by cloud contamination, sensitivity to seasonal variations of atmospheric water vapor, and the presence of aerosols (Huete et al. 2006). As a result, many of the pixels with daily NDVI measurements are indecipherable and the obtained NDVI fields are irregular. Long-term averages of NDVI measurements help to reduce such errors (NASA Earth Observatory; https://earthobservatory.nasa.gov/features/ MeasuringVegetation/measuring_vegetation_4.php).

VSM and zonal and meridional components of the 850-hPa winds ( $u$ and $v$, respectively) are obtained from
ERA5, provided by the European Centre for MediumRange Weather Forecasts (ECMWF) at a spatial resolution of $0.25^{\circ} \times 0.25^{\circ}$ during the period 1979-2019 (Hersbach and Dee 2016; Hersbach et al. 2020). VSM is provided at four different layers: layer 1 (L1): 0-7 cm, layer 2 (L2): $7-28 \mathrm{~cm}$, layer 3 (L3): $28-100 \mathrm{~cm}$, and layer 4 (L4): $100-289 \mathrm{~cm}$.

To compare ERA5 estimates of VSM, we use the equivalent water thickness estimated by the Gravity Recovery and Climate Experiment (GRACE), which is considered as a proxy of TWS in the continental regions shown in Fig. 1. The GRACE mission consists of twin satellites that measure changes in Earth's gravity field due to displacement of water, air, or landmasses. The values of equivalent water thickness provided by GRACE correspond to anomalies relative to the 200409 time-mean baseline and cannot be considered as absolute values of water storage (Swenson and Wahr 2006). We use the RL06 Level-3 v3 version of monthly 
time-variable gravity data with spherical harmonic coefficients up to $1^{\circ}$, with a spatial resolution of $\sim 1^{\circ} \times \sim 1^{\circ}$ and a monthly time step. We use the term TWS as the spatially averaged equivalent water thickness over the continental regions (Fig. 1) considering three products of equivalent water thickness developed by different research centers and laboratories: The Jet Propulsion Laboratory (JPL), the University of Texas Center for Space Research (CSR), and the GeoForschungsZentrum (GFZ) Potsdam. The RL06 v3 data used in this work correspond to monthly records from CSR, JPL, and GFZ data from April 2002 to June 2017 (available at https://podaac-tools.jpl.nasa.gov/drive/files/allData). Then, the mean of equivalent water thickness from the three products is considered as the monthly TWS over the specific region. Thus, changes in TWS represent the domainaverage change in water storage over the region on a monthly time scale. For more details about the GRACE dataset and their applications, see Chen et al. (2010), Frappart et al. (2012), Papa et al. (2008), and Xavier et al. (2010), among others. Previous studies have shown the capacity of GRACE to depict continental water storage variations at large spatial scales, including hydroclimatic variability in the Amazon subbasins (Frappart et al. 2013; Espinoza et al. 2019b) and hydrological modeling (Getirana et al. 2011; Ramillien et al. 2008; Siqueira et al. 2018; Tapley et al. 2004).

In addition, we use VSM estimates from the ERA5Land dataset for the same four soil layers retrieved by ERA5. ERA5-Land VSM has a spatial resolution of $0.1^{\circ}$ and covers the period 1981-2019 (Copernicus Climate Change Service 2019). ERA5-Land is forced by the atmospheric analysis of ERA5 and is based on running the land component of the model driven by, but without coupling to, the atmospheric models (Cao et al. 2020).

We also use precipitation data from the Climate Hazards Group Infrared Precipitation with Stations (CHIRPS), which is based on global cold cloud duration as a primary source for calculating precipitation at a global scale (Funk et al. 2015). This dataset covers the period 1981-2017 at a horizontal resolution of $0.5^{\circ} \times 0.5^{\circ}$ (available at http://chg.geog.ucsb.edu/data/chirps/).

For comparison, we use three additional datasets for precipitation. First, we use the Precipitation Estimation from Remotely Sensed Information using Artificial Neural Networks (PERSIANN) dataset (Ashouri et al. 2015), developed by the Center for Hydrometeorology and Remote Sensing (CHRS) at University of California, providing daily rainfall estimates with a spatial resolution of $0.25^{\circ} \times 0.25^{\circ}$ for the latitude band between $60^{\circ} \mathrm{N}$ and $60^{\circ} \mathrm{S}$ during the period between January 1983 and December 2015 (available at https://chrsdata.eng.uci.edu/). Second, we consider the Tropical Rainfall Measurement
Mission (TRMM) 3B43 V7 monthly dataset (Huffman et al. 1997), with data available from 1998 to 2015 and a spatial resolution of $0.25^{\circ}$ (available at http://mirador.gsfc.nasa.gov/). Third, we use precipitation data from ERA5 which covers the period 1979-2019 at a spatial resolution of $0.25^{\circ} \times 0.25^{\circ}$ (Hersbach and Dee 2016; Hersbach et al. 2020). This dataset is considered to verify the consistency between ERA5 estimates and observational datasets.

We estimate precipitable water contributions from different oceanic and continental sources using the Dynamic Recycling Model (DRM), as presented by Martinez and Dominguez (2014), with vertically integrated moisture flux. DRM is a semi-Lagrangian 2D model that estimates the exchange of water vapor from different sources, based on the principle of conservation of mass applied to a column of atmosphere, under the assumption of a wellmixed atmosphere. In particular, we consider oceanic source regions located in the Atlantic Ocean and continental source regions located in South America (Fig. 1a). To estimate contributions of precipitable water from each particular source region, DRM requires the use of 6-hourly data for precipitation, evaporation, vertically integrated zonal and meridional moisture fluxes, and precipitable water. These variables are obtained from ERA-Interim (Dee et al. 2011) for the period $1980-2015$ at a spatial resolution of $0.75^{\circ} \times 0.75^{\circ}$ (available at https://cds.climate.copernicus.eu/cdsapp\#!/ dataset/reanalysis-era5-land-monthly-means?tab=overview). More details regarding the DRM and its applications in regional moisture budget studies can be found in previous works (Agudelo et al. 2018; Arias et al. 2015b; HerreraEstrada et al. 2019; Hoyos et al. 2019; Martinez and Dominguez 2014; Roy et al. 2019).

\section{b. Methodology}

We compute correlations between the anomaly of SST and the different variables considered (precipitation, VSM at different layers, TWS, and NDVI) for the period January 1982-December 2015, since this corresponds to the common period among datasets. Anomalies are computed for each grid point by removing multiannual monthly means for each month of the year. We estimate correlations between indices of domain-average SST anomalies (SSTAs) for the different ocean regions defined in Fig. 1 and the domain average of each considered variable (precipitation, VSM, TWS, and NDVI) for each continental region defined in Fig. 1. Trends are removed from anomaly time series before computing correlations. The statistical significance of correlations is tested using a bootstrap test with 1000 iterations (Efron 1992).

SST anomalies are computed over several regions of the Atlantic Ocean selected according to different studies of atmospheric moisture sources to South America (Agudelo 
et al. 2018; Arias et al. 2015b; Hoyos et al. 2019; Martinez and Dominguez 2014; Nieto et al. 2008; Satyamurty and Priscila 2013). Figure 1a shows the oceanic regions considered to estimate domain-average SSTAs: Gulf of Mexico (GOM), northern Atlantic (NATL), Caribbean Sea (CABN), tropical North Atlantic (TNA), and tropical South Atlantic (TSA).

Precipitation, VSM, TWS, and NDVI are analyzed over different regions of the Orinoco and Amazon basins. According to differences in land cover, as well as climate and NDVI variability (see section $3 \mathrm{a}$ ), we consider different subregions in these basins. In particular, the Amazon basin is divided into four subregions. First, we define the northern (NAMZ) and central (CAMZ) Amazon, considering differences in their precipitation annual cycles (Espinoza et al. 2009b; Marengo 2005) and their contributions as moisture sources to South America (Agudelo et al. 2018; Arias et al. 2015b; Hoyos et al. 2019; Martinez and Dominguez 2014). A third subregion is the so-called Arc of Deforestation (ADEF), which includes the southern Amazon and constitutes an important focus of deforestation in the Amazon River basin (Aguiar et al. 2016; Costa and Pires 2010; Fearnside and de Alencastro Graca 2006). This region is characterized by a larger presence of land-cover mosaics, with areas of shrubs and savannas along with some urban patches (Fig. 1b). Studies suggest that, in association with the high anthropic intervention in this region, the southern Amazon has experienced an increased frequency of longer dry seasons (Debortoli et al. 2015; Espinoza et al. 2019a; Fu et al. 2013). The spatial extent of this region is based on the map of tree cover fraction reported by Coe et al. (2013). Finally, the Andean piedmont/foothills (PMNT) is considered due to the differences in precipitation between the eastern slope of the Andes mountain range and the Amazon plains (Espinoza et al. 2015). In particular, the northwestern Amazon rain forest receives the maximum amount of rainfall, which then decreases toward the southeast (Espinoza et al. 2009b, 2015; Zhao et al. 2017). The PMNT region is delimited from the top of the Andes toward the $200 \mathrm{~m}$ above mean sea level (MSL) contour elevation.

For the Orinoco River basin, we define two regions: northern Orinoco (NORIC), characterized by the presence of tropical savannas, and southern Orinoco (SORIC), characterized by wooded vegetation that borders the northern Amazon basin (Fig. 1b).

We also analyze correlations between SSTAs and precipitable water contributions from different source regions to each continental region of interest. These contributions are estimated from DRM simulations (section 2a). To further understand the observed correlations between the different variables considered and SSTAs, we analyze the evolution of anomalies of Atlantic SSTs as well as precipitation, precipitable water contributions, surface winds, VSM, TWS, and NDVI over the different continental regions during 2005 and 2010. These years correspond to two particular warm years in the tropical Atlantic Ocean and two very wellstudied drought years in the Amazon basin (Espinoza et al. 2011; Lewis et al. 2011; Marengo et al. 2011; Zeng et al. 2008).

\section{Results}

\section{a. NDVI climatology and variability}

Figures 2a-d show the climatological mean of AVHRR NDVI in tropical South America (north of $30^{\circ} \mathrm{S}$ ). The largest NDVI values within the Amazon basin occur during June-August (JJA; Fig. 2c), corresponding to the dry season in the southern Amazon. This can be explained by the close link between vegetation activity and the amount of incident solar radiation, which is greatest during the dry season, coinciding with changes in cloudiness and evapotranspiration over Amazonia (Arias et al. 2011; Li and Fu 2004; Wright et al. 2017; Yin et al. 2014). Evapotranspiration in the eastern Amazon rain forest is relatively high, with slightly smaller but similarly variable values during the rainy season (daily average of $3.96 \pm 0.65 \mathrm{~mm} \mathrm{day}^{-1}$ during the dry season and $3.18 \pm$ $0.76 \mathrm{~mm} \mathrm{day}^{-1}$ during the rainy season). Amazon $\mathrm{CO}_{2}$ assimilation capacity also increases during the dry season (da Rocha et al. 2004). This suggests that photosynthetic capacity is enhanced during the dry season relative to the wet season, generating a higher NDVI. Figure $2 \mathrm{~d}$ shows a slight reduction in NDVI over the southern Amazon basin during September-November (SON), corresponding to the transition between dry and wet seasons.

On the other hand, the largest NDVI values in the Orinoco River basin are over its northern region (Figs. 2a-d), coinciding with the geographical location of the Venezuelan Llanos. These plains are mainly composed of tropical savannas that cover part of central Venezuela and western Colombia, between latitudes $3^{\circ}$ and $9^{\circ} \mathrm{N}$ and longitudes $63^{\circ}$ and $73^{\circ} \mathrm{W}$, and have an altitude of approximately 300 MSL. Figure 2 shows that the largest NDVI values over the northern Orinoco are observed during JJA and SON (Figs. 2c,d, respectively), coinciding with the rainy season in this region. The smallest NDVI values are observed in December-February (DJF; Fig. 2a) and March-May (MAM; Fig. 2b), which correspond to the dry season. This seasonal cycle indicates that vegetation photosynthesis peaks during the rainy season, which is 
a) DJF Mean

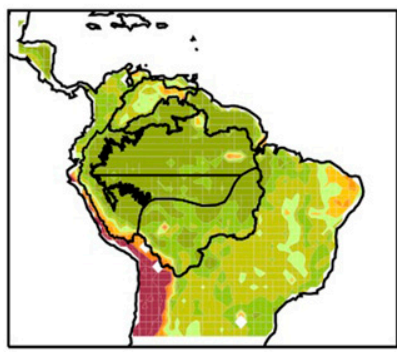

b) MAM Mean

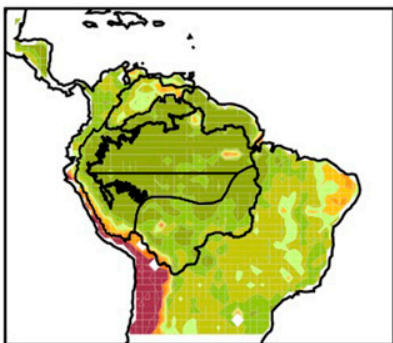

c) JJA Mean

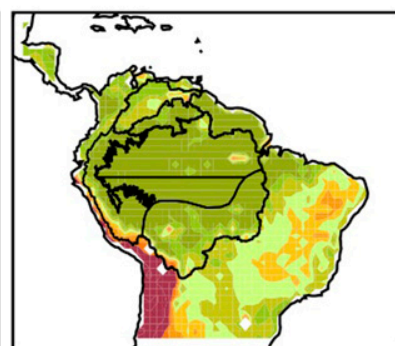

d) SON Mean

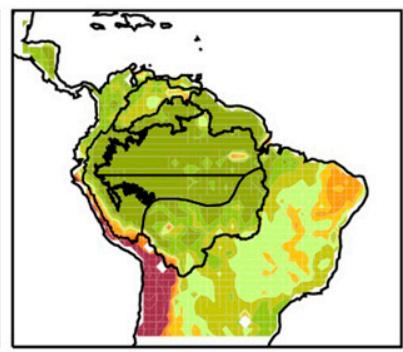

0.1

0.2

0.3

0.4

0.5

0.6

0.7

0.8

e) DJF Standard Deviation

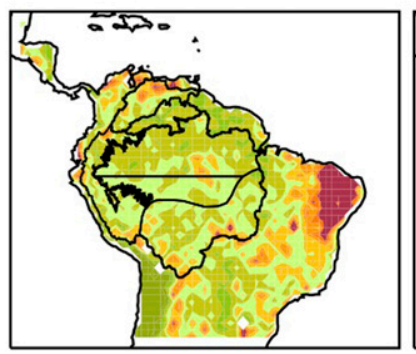

f) MAM Standard Deviation

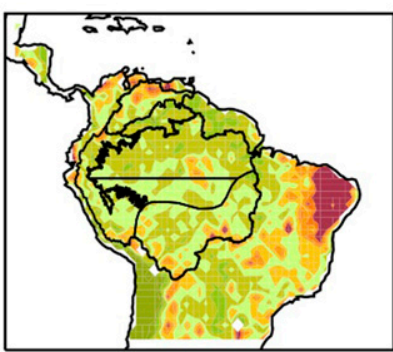

g) JJA Standard Deviation

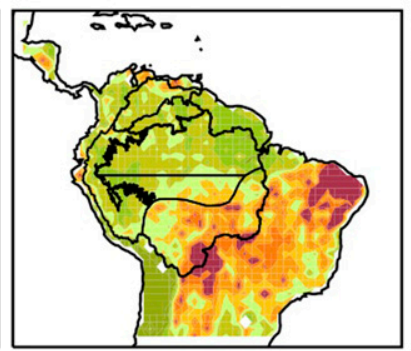

h) SON Standard Deviation

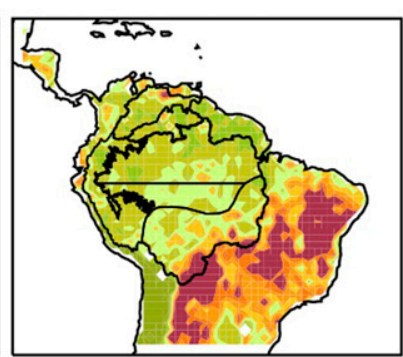

0.01

0.02

0.03

0.04

0.05

0.06

0.07

0.08

FIG. 2. Seasonal climatological (top) mean and (bottom) standard deviation of AVHRR NDVI for the period 1982-2015. Polygons delimit the six continental subregions of interest: northern Amazon (NAMZ), central Amazon (CAMZ), northern Orinoco (NORIC), southern Orinoco (SORIC), Arc of Deforestation (ADEF), and Andean Piedmont (PMNT) shown in Fig. 1.

consistent with expectations for savanna regions like the Orinoco River basin (Hilker et al. 2014).

Figures $2 \mathrm{e}-\mathrm{h}$ shows the climatological standard deviation of seasonal-mean AVHRR NDVI in tropical South America over 1981-2015. The largest standard deviation values are observed over the Brazilian Cerrado and the Nordeste region throughout the entire year. However, NDVI variability is also large in JJA (Fig. $2 \mathrm{~g}$ ) and SON (Fig. 2h) over the Arc of Deforestation, including southern Brazil and the Bolivian Amazon basin. The smallest standard deviations are observed in the northern part of the Amazon basin, characterized by a more regular annual cycle of rainfall (Espinoza et al. 2009b; Marengo 2005).

In the Orinoco River basin, the largest variability is observed during DJF (Fig. 2e) and MAM (Fig. 2f) in the northern region, where the vegetation is mostly shrubs, grasses, and savanna (Fig. 1b). SON (Fig. 2h) exhibits the lowest NDVI variability in this region. The larger variability over the northern Orinoco (or Los Llanos region) during DJF (Fig. 2e) and MAM (Fig. 2f) can be explained by the reduction of photosynthesis observed during the dry season in this region (Hilker et al. 2014). By contrast, the southern Orinoco basin seems to be more closely coupled to the variability of the northern Amazon, which is dominated by forest vegetation (Fig. 1b).

\section{b. Correlations between Atlantic SSTs and NDVI anomalies}

We compute lagged correlations between indices of domain-average SSTAs for the ocean regions shown in Fig. 1 and domain-average anomalies of the different variables (precipitation, VSM, TWS, and NDVI) for each continental region shown in Fig. 1. Since our focus is to understand the link between SSTAs and NDVI, we focus on the statistically significant correlations between these two variables. The largest correlations between NDVI and SSTAs are observed for the CABN and TNA regions. Therefore, we focus on correlations with SSTAs over these two particular oceanic regions.

Figures 3 and 4 show the lagged correlations between CABN/TNA SSTAs and domain-average NDVI anomalies for NORIC, CAMZ, and ADEF. Figures S1 and S2 in the online supplemental material show these correlations 
NORIC

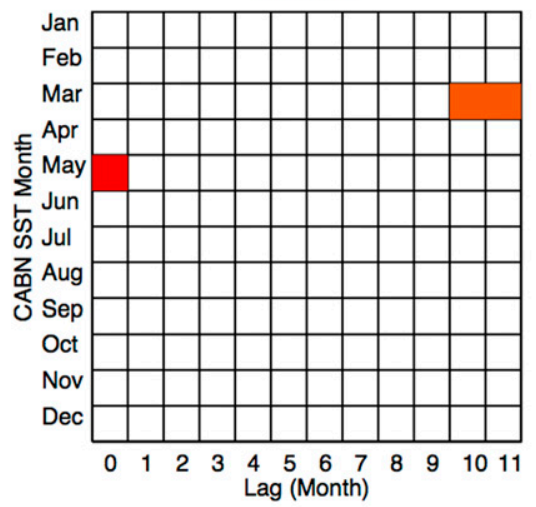

CAMZ

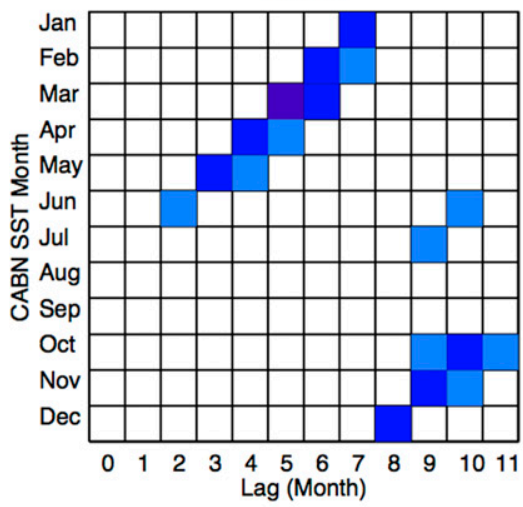

ADEF

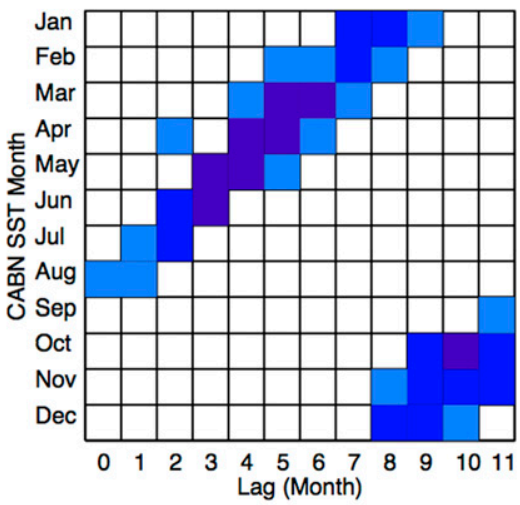

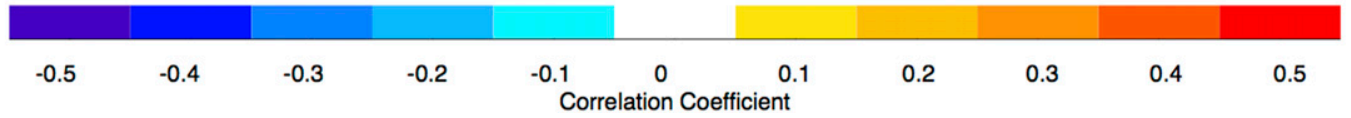

FIG. 3. The 1982-2015 lagged correlations between Caribbean Sea (CABN) SSTAs and NDVI anomalies averaged over (left) NORIC, (center) CAMZ, and (right) ADEF. Only statistically significant correlations are shown. Positive lags indicate that SST anomalies lead NDVI anomalies. The vertical axis indicates the month corresponding to the SSTAs while the horizontal axis represents the lag of the response in NDVI. For instance, the center panel indicates that CABN SSTAs during June are significantly correlated with NDVI in the central Amazon (CAMZ) with a lag of 2 months (i.e., August).

for the SORIC, NAMZ, and PMNT regions. The vertical axis indicates the month corresponding to the SSTAs while the horizontal axis represents the lag of the response in NDVI. For instance, the center panel in Fig. 3 indicates that CABN SSTAs during June are significantly correlated with NDVI in the central Amazon with a lag of 2 months. This means that CABN SSTAs in June are significantly correlated with central Amazon NDVI in August ( 2 months after). In general, Fig. 3 indicates that CABN SSTs during the period October to July are significantly related with NDVI anomalies over the central Amazon and the Arc of Deforestation with a lag about 1-7 months, which corresponds to the months of August-September, with correlation coefficients between -0.3 and -0.5 (Fig. 3).
NORIC

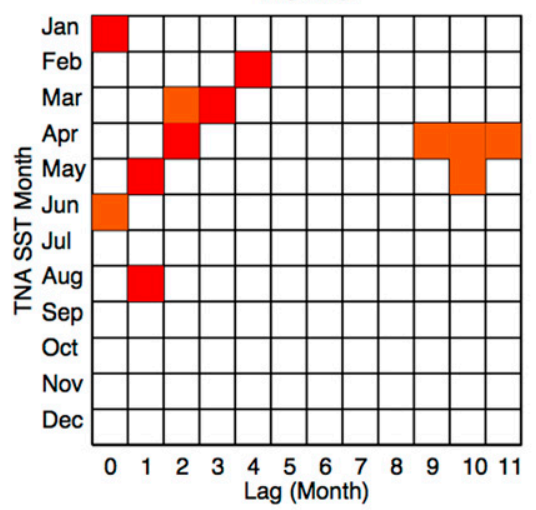

CAMZ

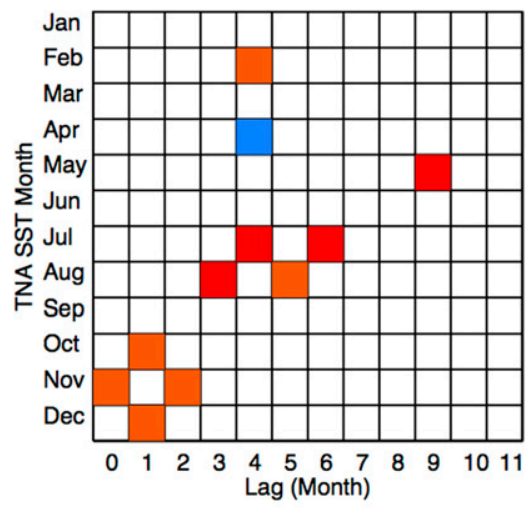

ADEF

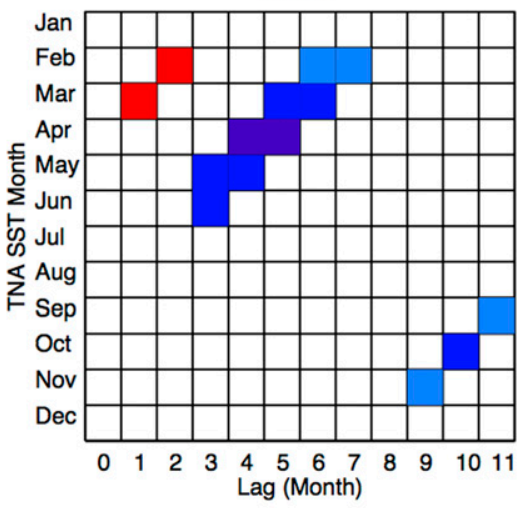

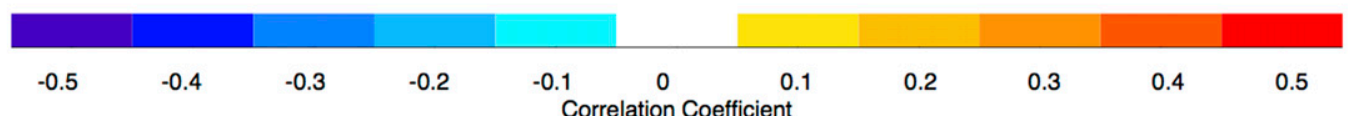

FIG. 4. The 1982-2015 lagged correlations between tropical North Atlantic (TNA) SSTAs and NDVI anomalies averaged over (left) NORIC, (center) CAMZ, and (right) ADEF. Only statistically significant correlations are shown. Positive lags indicate that SST anomalies lead NDVI anomalies. The vertical axis indicates the month corresponding to the SSTAs while the horizontal axis represents the lag of the response in NDVI. For instance, the right panel indicates that TNA SSTAs during February are significantly correlated with NDVI in the northern Orinoco (NORIC) with a lag of 4 months (i.e., June). 

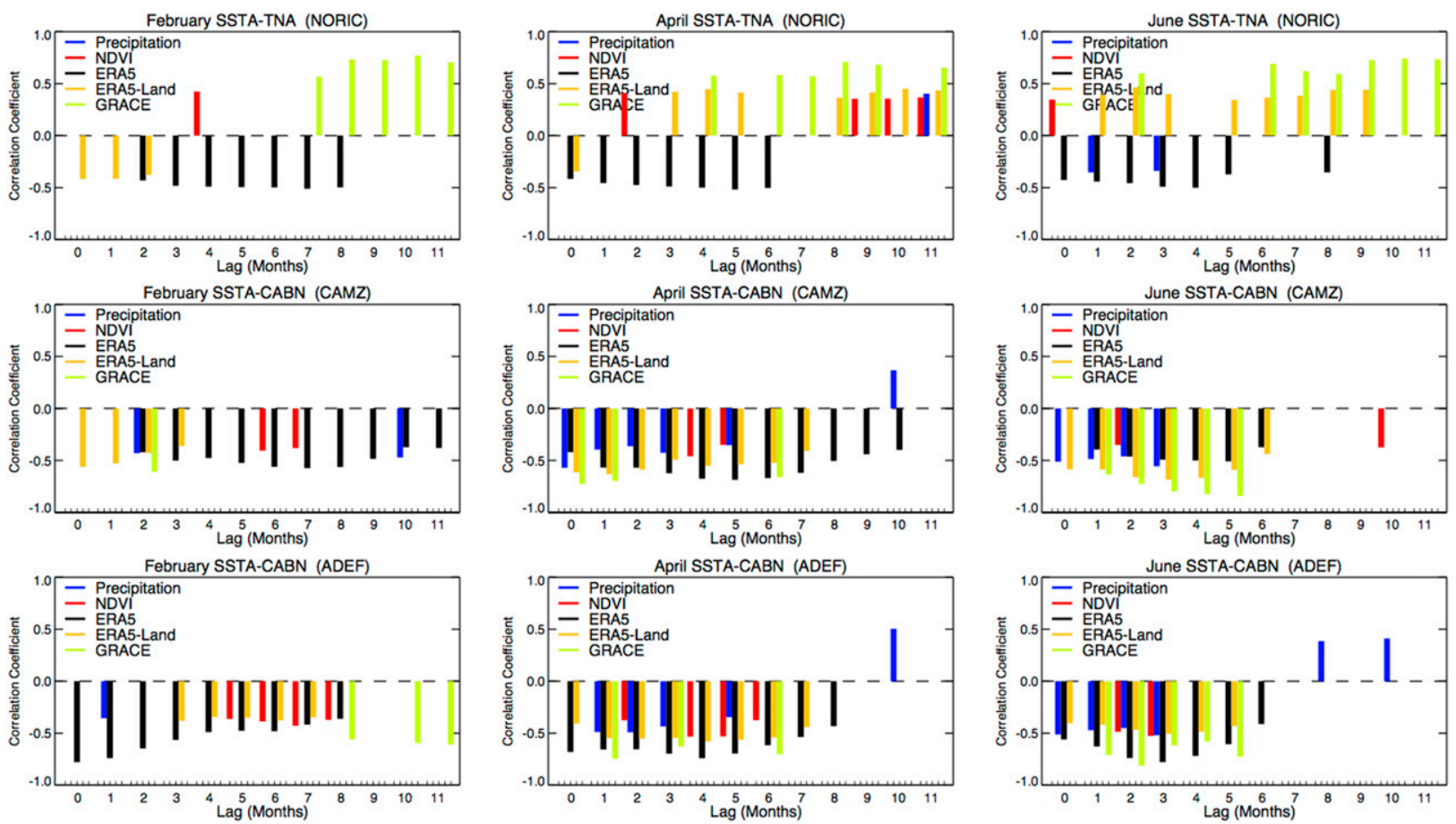

FIG. 5. (top) The 1982-2015 lagged correlations between tropical North Atlantic (TNA) SSTAs and CHIRPS precipitation (blue), NDVI (red), ERA5 VMSL4 (black), ERA5-Land VMSL4 (orange), and GRACE TWS (green) anomalies averaged over NORIC. (middle),(bottom) As in the top panel, but for CAMZ and ADEF, respectively. Correlations with TWS are computed for the period 200315, due to TWS data availability. Only statistically significant correlations are shown. Positive lags indicate that SST anomalies lead other variables. The vertical axis indicates the correlation coefficient while the horizontal axis shows the lag of response of the correspondent variable. Each panel shows the correlations for SSTAs in different months: (left) February, (center) April, and (right) June. Therefore, the horizontal axis indicates the lag of response with respect to the month when SSTAs are observed. For instance, the top-right panel corresponds to correlations with February TNA SSTAs and NDVI in the northern Orinoco (NORIC). NDVI shows a positive correlation with a lag of 4 months. This means that February TNA SSTAs are significantly correlated with NDVI in the northern Orinoco during June (4 months after).

NDVI variations in the other Amazonian regions (northern Amazon and Andean Piedmont) do not show a statistically significant response to CABN SSTAs (Fig. S1).

NDVI in the Arc of Deforestation shows a negative link during August-September with respect to TNA SSTAs observed during most of the year (Fig. 4). Therefore, the Arc of Deforestation is the Amazonian region where NDVI shows the largest response to both CABN and TNA SSTAs.

For the Orinoco basin, the strongest correlation patterns are observed over the northern Orinoco, where vegetation in June responds to TNA SST anomalies observed during the $1-5$ preceding months (February to June; Fig. 4). Unlike southern Amazonia and the Arc of Deforestation, northern Orinoco vegetation is positively linked with TNA SSTs (correlation coefficients close to 0.5 ), suggesting that a warmer (cooler) TNA is related to enhanced (reduced) NDVI in this region. By contrast, this region does not show a significant response to CABN SSTAs. NDVI in the southern Orinoco does not show significant correlations with CABN or TNA SSTAs (Figs. S1 and S2).

\section{c. Correlations between Atlantic SSTs and other variables}

Figures 3 and 4 suggest that the NDVI in the central Amazon and the Arc of Deforestation (northern Orinoco) respond more strongly to the CABN (TNA) SSTAs observed during March-June. In addition, NDVI in the Arc of Deforestation exhibits significant links with both CABN and TNA SSTAs. Therefore, Fig. 5 shows the lagged correlations between TNA (CABN) SSTAs in February, April, and June, and domain-average NDVI, CHIRPS precipitation, VSM, and TWS in northern Orinoco (central Amazon and Arc of Deforestation) for different lags.

Figure 5 shows the lagged correlations between CABN/TNA and domain-average CHIRPS precipitation, ERA5 VSML4, and GRACE TSW. The vertical axis indicates the correlation coefficient while the horizontal axis shows the lag of the response in the corresponding 
variable. Each panel shows the correlations for SSTAs in different months (February, April, and June). Therefore, the horizontal axis indicates the lag of the response with respect to the month when SSTAs are observed. For instance, the top-right panel in Fig. 5 corresponds to correlations with February TNA SSTAs and NDVI in the northern Orinoco. NDVI shows a positive correlation with a lag of 4 months. This means that February TNA SSTAs are significantly linked with NDVI in the northern Orinoco during June (4 months after). Figure 5 indicates that TNA SSTAs during March-June do not exhibit a significant relationship with precipitation in the northern Orinoco. The only significant correlation coefficients are between June SSTAs and precipitation in July and September, corresponding to 1 and 3 months after the peak response of NDVI in the northern Orinoco to TNA SSTAs (which is observed in June).

By contrast, CABN SSTAs during March-June are negatively linked with precipitation in the central Amazon and the Arc of Deforestation during the months between April and September, indicating that precipitation is reduced in these regions during the wetto-dry transition and dry seasons when Caribbean SSTs are warmer. These results are also observed when considering PERSIANN, TRMM, or ERA5 precipitation (Fig. S3), indicating that this result does not depend on the precipitation dataset considered.

Correlations between SSTAs and ERA5 VSM indicate that soil moisture at deep layers (VSML4: depths between 100 and $289 \mathrm{~cm}$ ) in the northern Orinoco (central Amazon and Arc of Deforestation) is reduced with warmer temperatures in the TNA (CABN) (Fig. 5). This relationship is observed only for VSM at the deepest layers, since correlations for shallower layers (VSML1 to VSML3) are not statistically significant (Fig. S4). In particular, for the central Amazon and the Arc of Deforestation, warmer CABN SSTAs during March-June are associated with reduced VSML4 starting from February-April and with persistence up to 10 months in the central Amazon and 8 months in the Arc of Deforestation. This is also supported by correlations with TWS, mainly as a response to CABN SSTAs during April-June (Fig. 5). This agreement suggests that soil moisture in the central Amazon estimated by the ERA5 surface model exhibits a reasonable performance regarding interannual variability and its connection with Atlantic SSTAs, relative to GRACE satellite estimates (Fig. 5). Also, the fact that ERA5 precipitation shows agreement in the interannual correlations between precipitation and SSTAs (Fig. S3) suggests that the correlations estimated for the central Amazon and the Arc of Deforestation seem not to be biased by the use of this reanalysis.
Despite this agreement, it is necessary to assess further validations of ERA5 soil moisture data since observational data in the Amazon are scarce, and ERA5 provides soil moisture discretized by levels, which is difficult to validate, although VSML4 is the widest (100$289 \mathrm{~cm}$ ) among the four soil layers provided by ERA5. Moreover, ERA5 includes only very limited vegetation seasonality (via a prescribed climatological annual cycle of the leaf area index; Boussetta et al. 2013), with no interannual variability and no seasonality in other parameters. This and other limitations may influence the performance of evaporation and VSM, especially in terms of year-to-year variability. Soil moisture is analyzed in ERA5 using a pointwise extended Kalman filter (de Rosnay et al. 2013) to assimilate conventional observations and soil moisture from scatterometers, but this assimilation only applies to the upper three soil layers in the surface model. This might explain why the soil moisture response to changes in rainfall is most pronounced in VSML4. Indeed, the consistency between GRACE (which considers all gravitational changes in the soil) and VSML4, even in deforested areas such as the Arc of Deforestation, and the fact that ERA5 VSM shows statistical links with SSTAs only for the deepest layer, is interesting. The consistency of the VSML4 with GRACE for the central Amazon/Arc of Deforestation is remarkable as a preliminary result; however, we still need to understand the links between soil moisture, precipitation, and SSTs, particularly in deforested areas.

By contrast, the responses of VSML4 and TWS in the northern Orinoco to TNA SSTAs are opposite (Fig. 5), even when considering the common period between both datasets (2003-15; not shown). This suggests that the ERA5 surface model may not adequately represent soil moisture in the northern Orinoco. ERA5 VSML4 in April-October over the northern Orinoco is reduced in association with warmer TNA SSTAs in March-June while GRACE TSW shows increased water storage in August-February. In particular, the increase in TWS suggested by GRACE occurs after the strongest response of NDVI to SSTAs (which is observed in June).

Given the lack of relationship between TNA/CABN SSTAs and ERA5 VSM in the northern Orinoco, as well as the lack of significant correlations for the shallower soil layers in the central Amazon and the Arc of Deforestation, we analyze correlations between SSTAs and ERA5-Land VSM for the same four soil layers retrieved by ERA5 (Fig. S5). In contrast to ERA5, ERA5Land shows significant correlations with SSTAs for the four soil layers considered, and not only for the deepest layer (VSML4; Fig. S5). This is observed not only in the central Amazon and the Arc of Deforestation but also in 
the northern Orinoco. In particular, for the northern Orinoco, ERA5-Land suggests that warmer SSTAs in the TNA during March-June are related to increased soil moisture in the northern Orinoco during May-July (Fig. S5). However, significant correlations for ERA5Land VSM occur about 1 month earlier than those observed for GRACE, which shows increased TWS, 1 month after the peak response of NDVI to TNA SSTAs (Fig. 5). The discrepancies between ERA5-Land and GRACE in the northern Orinoco needs to be further addressed, and they could be related to limitations in the HTESSEL scheme used in ERA5-Land, biases in atmospheric forcing fields, representation of a deeper soil column in the GRACE records compared to the soil layers in ERA5-Land, and/or lack of seasonality on the leaf area index (LAI) and its potential effects on ERA5-Land soil moisture, among others. However, it is interesting to see that the correlations in the Orinoco region are of the same sign and roughly with the same lags for ERA5Land and GRACE, in contrast to ERA5. In addition, note that the correlations are positive between SSTAs and soil moisture variables (as represented by GRACE and ERA5-Land) in the Orinoco region, while the opposite relationship is found for CAMZ and ADEF.

In summary, Figs. 3-5 suggest that warmer CABN SSTAs in March-June are related to decreased precipitation in April-September and decreased soil moisture in April-December over the central Amazon and the Arc of Deforestation. Consequently, Amazon NDVI is reduced during August-September in response to warmer CABN SSTAs in March-June.

NDVI in the northern Orinoco shows an increase during June due to warmer TNA SSTAs in March-June; however, precipitation does not exhibit a consistent response that allows us to link changes in NDVI to changes in this variable. The response of soil moisture in the northern Orinoco to SSTAs depends on the dataset considered. ERA5-Land suggests that soil moisture in the northern Orinoco increases during May-July in association with warmer SSTAs in the TNA during March-June. By contrast, ERA5 and GRACE do not support this link.

\section{d. Correlations between Atlantic SSTs and precipitable water contributions}

To further understand the observed response of precipitation, soil moisture, and NDVI over the northern Orinoco, central Amazon, and Arc of Deforestation regions to CABN and TNA SSTAs, we analyze precipitable water contributions to the Orinoco basin (ORIC) and southern Amazon (SoAmaz) sink regions. ORIC corresponds to the entire Orinoco River basin, which includes both NORIC and SORIC regions (Fig. 1). SoAmaz corresponds to the portion of the Amazon
River basin located south of $5^{\circ} \mathrm{S}$; therefore, it includes CAMZ, ADEF, and the PMNT region south of $5^{\circ} \mathrm{S}$ (Fig. 1). Precipitable water contributions are estimated using the DRM (section 2a).

Considering the climatological annual mean (19802015), the main moisture sources to ORIC are TNA $(43.5 \%)$, ORIC $(11.6 \%)$, and TSA $(8.8 \%)$ regions. The main moisture sources to SoAmaz are SoAmaz (27.2\%), TSA (20.3\%), the northern Amazon basin (NoAmaz; $9.2 \%$ ), and TNA (7.7\%). Figure 6 shows the lagged correlations between TNA SSTAs and anomalous precipitable water contributions from the TNA, TSA, ORIC, and SoAmaz source regions to the ORIC and SoAmaz sink regions. The interpretation of this figure is similar to Fig. 5. Figure 6 indicates that warmer TNA SSTAs in March-June are associated with increased precipitable water contributions from TSA to ORIC in April-June and reduced contributions from TNA to ORIC in June. Moreover, atmospheric moisture recycling (i.e., contributions from ORIC to itself) are enhanced during June. Hence, both atmospheric moisture transport from the TSA and moisture recycling in ORIC during June are enhanced with warmer conditions in the TNA during the previous months. However, these increases could be offset by decreases in contributions from the TNA in June. This could explain the lack of response of precipitation in NORIC (and also SORIC; not shown) to TNA SSTAs (Figs. 5 and S3). On the other hand, the increased moisture recycling in ORIC in June as a response to MarchJune TNA SSTAs could be related to enhanced evapotranspiration and vegetation activity (therefore NDVI) in this region, consistent with the stronger positive NDVI response to TNA SSTAs observed during June in the northern Orinoco (Fig. 4). However, the causality between these changes needs to be further explored.

For the SoAmaz region (which includes both the central Amazon and the Arc of Deforestation), warmer CABN SSTAs in March-June are related to decreased precipitable water contributions from TNA and NoAmaz (not shown) in April and increased contributions from TSA in March-May (Fig. 6). Furthermore, moisture recycling in SoAmaz is reduced during September-October in association with warmer SSTAs in March-June. This is consistent with the negative correlations between MarchJune SSTAs and NDVI in the central Amazon and the Arc of Deforestation during August-September (Fig. 4), since reduced moisture recycling may result from reduced evapotranspiration and vegetation activity.

\section{e. Evolution of anomalies during extreme drought years}

Figures 3-6 suggest that dry season NDVI over the central Amazon and the Arc of Deforestation (August-September) 

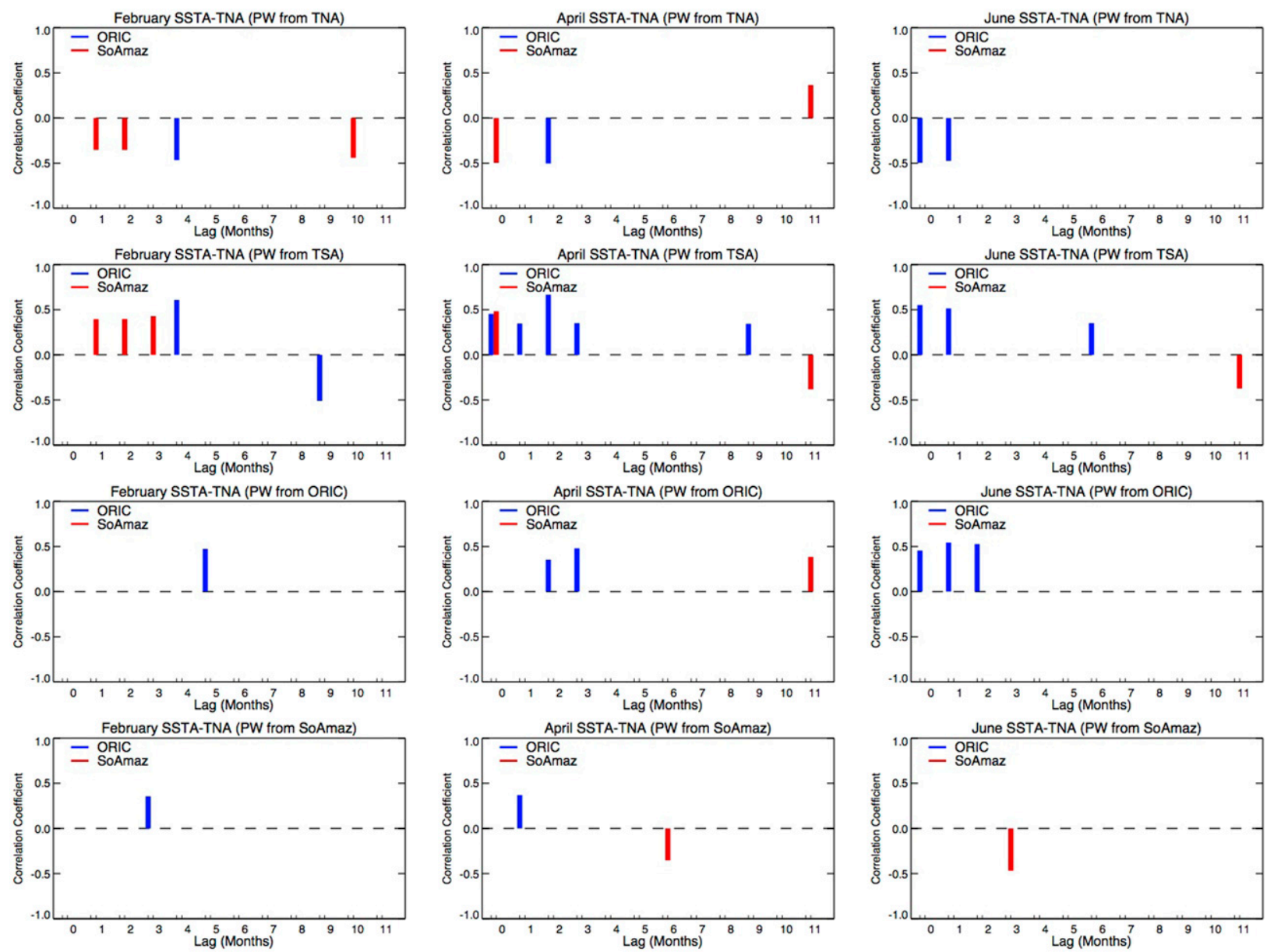

FIG. 6. The 1982-2015 lagged correlations between tropical North Atlantic (TNA) SSTAs and anomalies of precipitable water (PW) contributions from (top to bottom) TNA, TSA, ORIC, and SoAmaz source regions to ORIC (blue) and SoAmaz (red) sink regions. The ORIC and SoAmaz source regions differ from the NORIC and CAMZ regions shown in Fig. 1. ORIC includes both the NORIC and SORIC regions. SoAmaz includes CAMZ, ADEF, and the PMNT region south of $5^{\circ} \mathrm{S}$. Only statistically significant correlations are shown. Positive lags indicate that SST anomalies lead PW anomalies. The vertical axis indicates the correlation coefficient while the horizontal axis shows the lag of response of PW. Each panel shows the correlations for SSTAs in different months: (left) February, (center) April, and (right) June. The horizontal axis indicates the lag of response with respect to the month when SSTAs are observed. For instance, the topright panel corresponds to correlations with February TNA SSTAs and PW contributions from TNA. PW contribution from TNA to SoAmaz shows a negative correlation with a lag of 1-2 months (March-April) with respect to February TNA SSTAs.

is negatively correlated with Atlantic SSTAs in MarchJune. By contrast, NDVI in the northern Orinoco during June (wet season) is positively correlated with Atlantic SSTAs in March-June. NDVI anomalies in the northern Amazon and southern Orinoco regions do not show significant correlations with SST anomalies over the regions of the Atlantic considered here.

Reductions of vegetation activity in the southern Amazon in association with warmer Atlantic SSTs have been widely reported (Espinoza et al. 2016; Marengo et al. 2008, 2011; Zeng et al. 2008). In particular, a warmer TNA induces changes in the Hadley cell and subsidence over the central and the southwestern Amazon (Arias et al. 2015b; Espinoza et al. 2016), favoring droughts and reduced vegetation activity. Studies focused on the impacts of Atlantic SSTs on Orinoco vegetation are scarcer. Different studies suggest that warmer Atlantic SSTs induce enhanced precipitation over northern South America (including the northern Amazon and Orinoco basins) (Barichivich et al. 2018; Espinoza et al. 2019a), as occurred during 2010-11 (Arias et al. 2015b; Trenberth and Fasullo 2012). However, these studies did not address the effects of SST variability on vegetation.

To further understand the correlations depicted by Figs. 3-6, we analyze the evolution of anomalies in SSTs, surface winds, precipitable water contributions, precipitation, VSML4, and NDVI during the two warmest 
a) SSTA February 2005

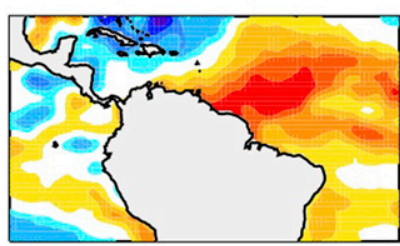

e) SSTA April 2005

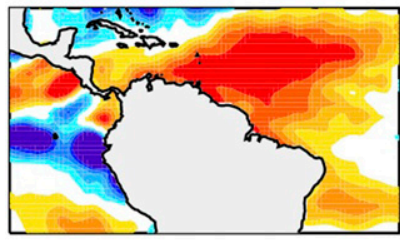

i) SSTA June 2005

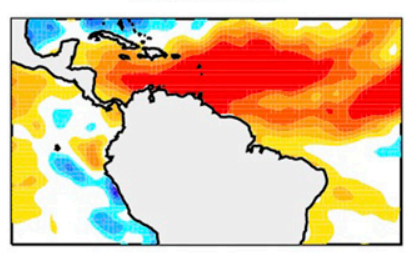

m) SSTA August 2005

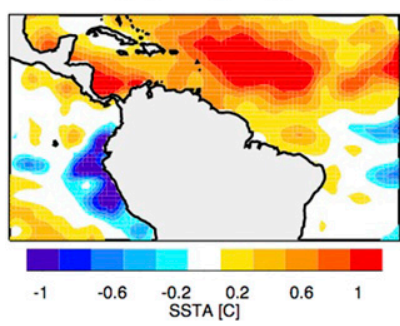

b) Precipitation February 2005

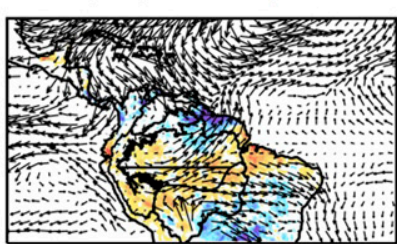

f) Precipitation April 2005

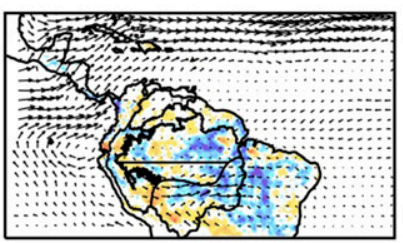

j) Precipitation June 2005

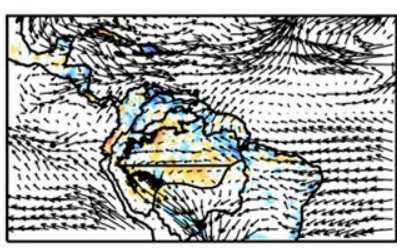

n) Precipitation August 2005

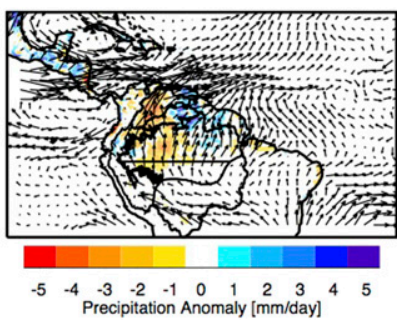

c) VSML4 February 2005

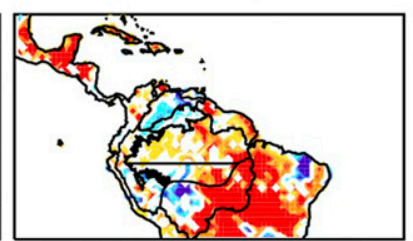

g) VSML4 April 2005

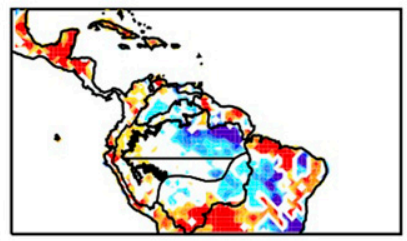

k) VSML4 June 2005

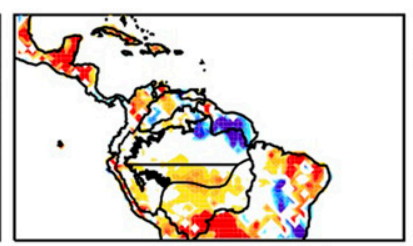

o) VSML4 August 2005

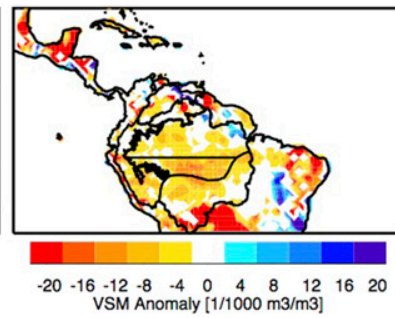

d) NDVI February 2005

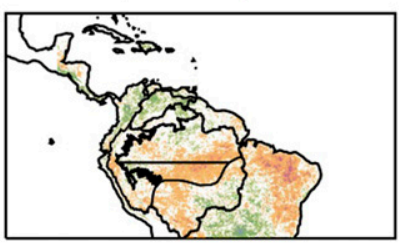

h) NDVI April 2005

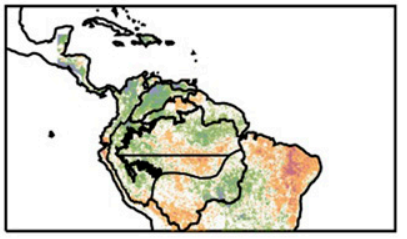

I) NDVI June 2005

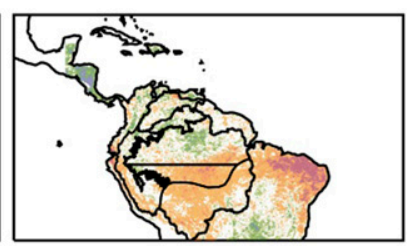

p) NDVI August 2005

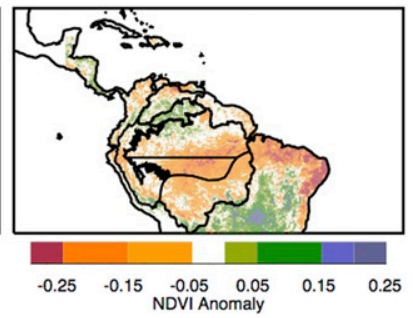

FIG. 7. Detrended anomalies of (first column) SSTs, (second column) 850-hPa winds (vectors) and precipitation (shading), (third column) ERA5 VSML4, and (fourth column) NDVI during (a)-(d) February, (e)-(h) April, (i)-(l) June, and (m)-(p) August 2005. Polygons delimit the six continental subregions of interest: northern Amazon (NAMZ), central Amazon (CAMZ), northern Orinoco (NORIC), southern Orinoco (SORIC), Arc of Deforestation (ADEF), and Andean Piedmont (PMNT) shown in Fig. 1.

years in the Atlantic Ocean observed during the period 1982-2015. These two years (2005 and 2010) corresponded to extreme drought conditions in the Amazon basin. To rule out that the correlations observed between SSTAs and NDVI anomalies in the regions considered are due to the inclusion of these extreme droughts, we compute correlations excluding data for 2005 and 2010 (Figs. S6 and S7). Results indicate that the correlations shown in Figs. 3 and 4 are not biased by the inclusion of these years.

The 2005 Amazon drought was due to a prolonged dry season, especially in the southern and southwestern Amazon, and is considered one of the most severe droughts in at least 100 years (Lewis et al. 2011; Marengo et al. 2008). These conditions intensified until September 2005 (Fig. 7), when atmospheric humidity was lower than normal and air temperatures were $3^{\circ}$ to $5^{\circ} \mathrm{C}$ higher than climatological conditions. The 2010 Amazon drought, unlike the 2005 drought, affected the entire Amazon basin (Fig. 9). This drought began during El Niño 2009-10, at the beginning of austral summer (DJF), and became more intense as warm conditions in the TNA persisted throughout austral winter (Fig. 9; first column) (Espinoza et al. 2011; Marengo et al. 2011). As observed during the 2005 drought, the warming of the TNA in 2010 affected the hydrology of the Amazon basin during its dry season, with the greatest impacts centered in the southern and western Amazon (Fig. 9; third and fourth column). This fact is of particular importance since the affected area did not recover after the drought in 2005, with water deficits also recorded during the dry seasons of 2006 and 2007. The lingering consequences of the 2005 drought on precipitation and canopy structure in the southern and western Amazon (Saatchi 
(a) From TNA 2005-02

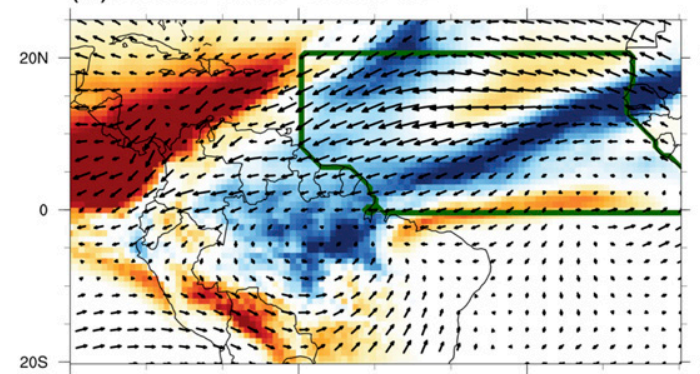

(b) From TSA 2005-02

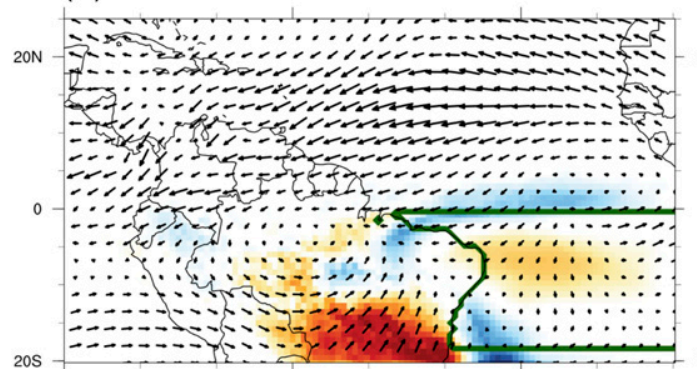

(c) From TSA 2005-03

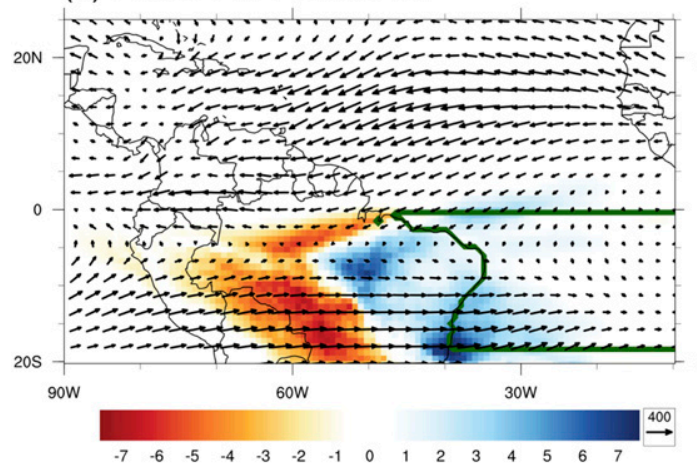

(d) From NoAmaz 2005-02

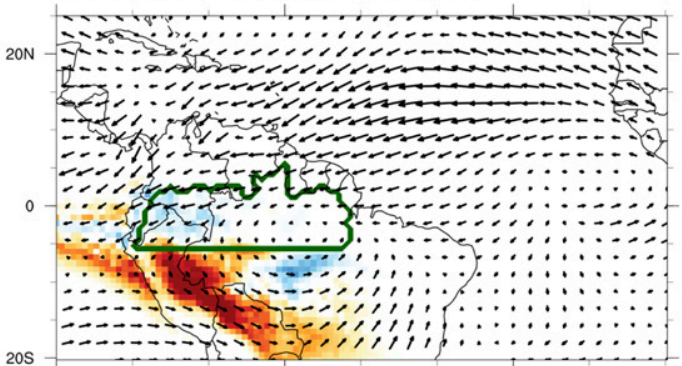

(e) From ORIC 2005-06

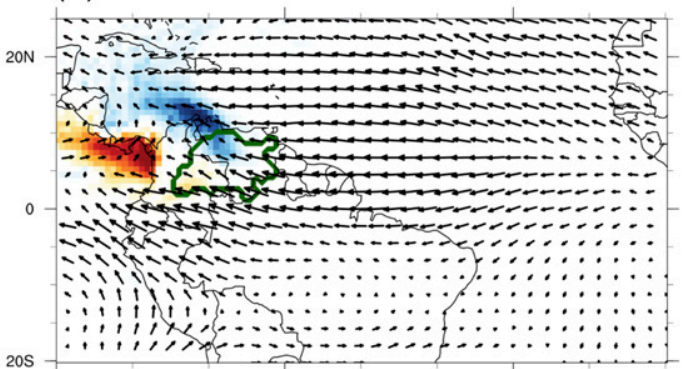

(f) From SoAmaz 2005-09

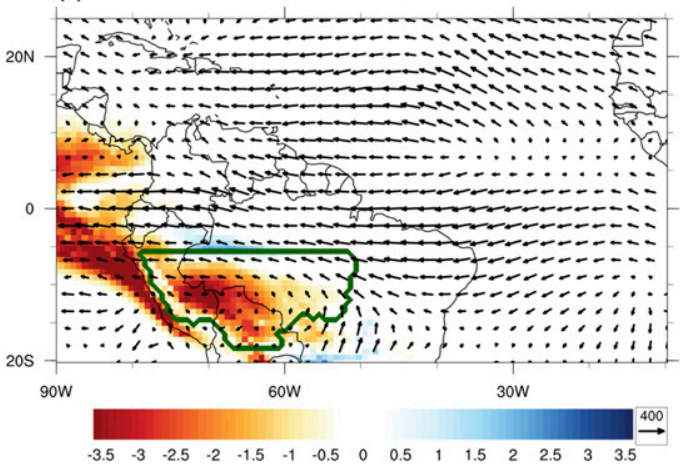

FIG. 8. Detrended anomalies of precipitable water contributions (shading, in $\mathrm{mm}$ ) from (a) the tropical North Atlantic (TNA) during February 2005; (b),(c) the tropical South Atlantic (TSA) during February and March 2005, respectively; (d) the northern Amazon (NoAmaz) during February 2005; (e) the Orinoco (ORIC) during June 2005; and (f) the southern Amazon (SoAmaz) during September 2005. Vectors indicate vertically integrated moisture flux (in $\mathrm{kg} \mathrm{m}^{-1} \mathrm{~s}^{-1}$ ). Green polygons correspond to the particular water vapor source region considered in the DRM simulation. TSA and TNA source regions correspond to the same domains shown in Fig. 1a. NoAmaz and SoAmaz source regions are not the same as the NAMZ and CAMZ regions shown in Fig. 1. The NoAmaz includes the NAMZ and PNMT region north of $5^{\circ} \mathrm{S}$. The SoAmaz includes CAMZ, ADEF, and the PNMT region south of $5^{\circ} \mathrm{S}$.

et al. 2013) thus meant that the 2010 drought intensified existing stresses on an already vulnerable vegetation population. The impacts of the 2010 drought were evident in the decreased river discharge by the Amazon River and its tributaries, increased surface temperatures and a drier atmosphere that favored increased evapotranspiration, especially during the dry season (JulySeptember). Temperature anomalies averaged over the region in 2010 reached $1^{\circ} \mathrm{C}$ (Marengo et al. 2011). A more detailed review of these two dry seasons has been provided by Marengo and Espinoza (2016).

\section{1) Anomalies in the central Amazon And THE ARC OF DEFORESTATION}

Figure 7 shows the spatial pattern of monthly anomalies for SST, precipitation, 850-hPa horizontal winds, ERA5 VSML4 and NDVI during 2005. Figure 8 shows anomalous precipitable water contributions from the TNA, TSA, ORIC, NoAmaz, and SoAmaz regions for specific months in 2005. According to Fig. 7 (first column), anomalous warming of the CABN and TNA reached its peak during April-June 2005 and then progressively 
decreased through August-September 2005. Precipitation anomalies during 2005 (Fig. 7, second column) indicate that the largest negative anomalies over the southern and western Amazon were observed during FebruaryJune. For April 2005, anomalies were located largely toward the western Amazon and the western Arc of Deforestation. In general, negative precipitation anomalies were concentrated in the western Amazon, particularly in the Solimões and Madeira basins, until September 2005, in agreement with the area most affected by this drought (Espinoza et al. 2011; Marengo et al. 2008). Figure 7 (second column) also shows a weakening of the NASH during early 2005, in association with a weakening of the trade winds that flow from the northeast toward the south. Conditions in 2005 also featured an anomalously weak SALLJ during the months of February, April, and August (Fig. 7, second column), in association with reduced atmospheric moisture fluxes from the tropical Atlantic (TNA and TSA) and the northern Amazon toward the southwestern Amazon, especially in February-March (wet season; Figs. 8a-d). This is consistent with the reductions of precipitation over the central Amazon and the Arc of Deforestation at the beginning of 2005 (Fig. 7, second column), which led to negative anomalies of soil moisture over these regions between April and August (Fig. 7, third column). Consistently, the central Amazon and the Arc of Deforestation showed negative NDVI anomalies between January and March 2005. A slight recovery of NDVI in April was then followed by further decreases through August-September, showing the largest negative NDVI anomalies in the region (Fig. 7, fourth column). This is in agreement with the low water levels in the southern and western Amazon tributaries (Upper Solimões and Madeira) (Espinoza et al. 2009a), and with the timing of the peak response of central Amazon vegetation to SST anomalies in the CABN and TNA according to the correlation analyses (Figs. 3-6). Such reductions in NDVI are consistent with reductions of local moisture recycling within the central and southern Amazon during September 2005 (Figs. 6 and 8e).

Previous studies suggest that warming of the TNA induces a pattern of anomalous ascent in northern South America, including the northern Amazon basin, and anomalous subsidence over the southern Amazon, reducing atmospheric moisture convergence and rainfall in the latter region. These changes are due to an alteration in the regional Hadley cell over the North Atlantic and tropical South America (Espinoza et al. 2019a; Yoon and Zeng 2010). The position of the ITCZ is also influenced by the higher SSTs over the Atlantic. For example, the warmer conditions of the tropical North Atlantic during 2010 induced an anomalous shift of the
ITCZ about $5^{\circ}$ northward of its climatological position, which contributed to the lack of rainfall in the central and eastern Amazon during March-May 2010 (Marengo et al. 2011; Yoon and Zeng 2010). Figure 9 (first column) shows that positive SST anomalies in the North Atlantic during 2010 were largest in April-June. Consequently, the NASH was weakened during these months. The associated weakening of the northeasterly trade winds toward the south in June 2010 (Fig. 9, second column) may have in turn affected SSTs in the TNA (BuilesJaramillo et al. 2018; Xie and Carton 2004; Yoon and Zeng 2010). As a consequence, atmospheric moisture transport to the Amazon was reduced as the ITCZ shifted northward (Fig. 10). Reductions in water vapor transport from the TNA were particularly pronounced over the western Amazon during March-April 2010 (Figs. 10a,b).

Consistently, Fig. 9 (second column) shows a dipole in precipitation anomalies between the equator and $10^{\circ} \mathrm{N}$ during April-June 2010, with an area of large positive precipitation anomalies to the north and a band of negative anomalies to the south. This dipole can be explained by the anomalous north-south divergent circulation observed in 2010, corresponding to the altered regional Hadley cell described above. Alteration of the Hadley cell resulted in anomalous ascent of warm air masses over the northern Atlantic and northern South America (positive precipitation anomalies) and subsidence of air masses south of the equator (negative precipitation anomalies), as reported by previous studies (Arias et al. 2015b; Trenberth and Fasullo 2012; Wang et al. 2018). The SALLJ was also anomalously weak during April-June 2010 (Fig. 9, second column), reducing atmospheric moisture transport from the tropical Atlantic (TNA and TSA) and the northern Amazon to the central and southern Amazon and the northern La Plata basin (Figs. 10a-d). Consistently, the negative precipitation anomalies were stronger in the central Amazon and the Arc of Deforestation during these months (Fig. 9, second column). Negative precipitation anomalies also emerged over the eastern Amazon in February 2010 (Fig. 9, second column), owing to the dynamical effects of the 2009/10 El Niño on the 2009/10 wet season (Marengo et al. 2011).

On the other hand, positive VSML4 anomalies were observed in the Amazon basin by early 2010 (Fig. 9, third column), which may be possible due to high rain rates in this region during 2009 (Saatchi et al. 2013). In particular, the Marañón basin in the western Amazon experienced major flooding (Espinoza et al. 2011). However, after the warming of the tropical North Atlantic by early 2010, negative anomalies of precipitation started to develop over the region, especially in the central Amazon and the Arc of Deforestation (Fig. 9, second column). Likewise, soil 


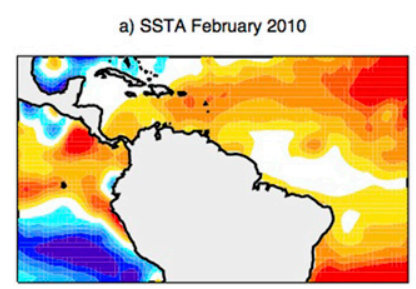

e) SSTA April 2010

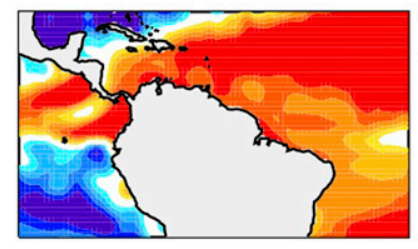

i) SSTA June 2010

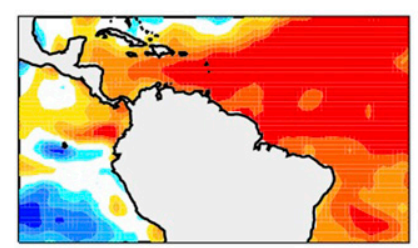

m) SSTA August 2010

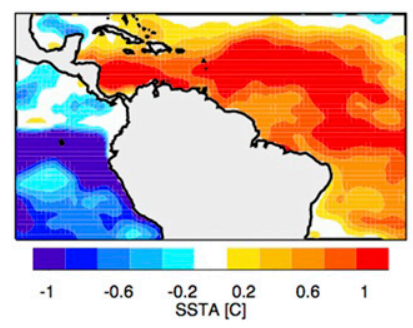

b) Precipitation February 2010

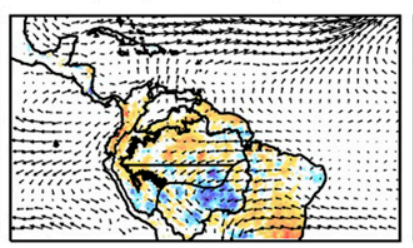

f) Precipitation April 2010

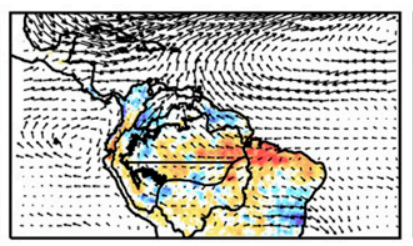

j) Precipitation June 2010

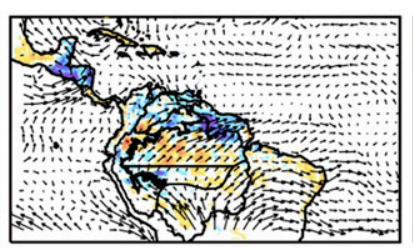

n) Precipitation August 2010

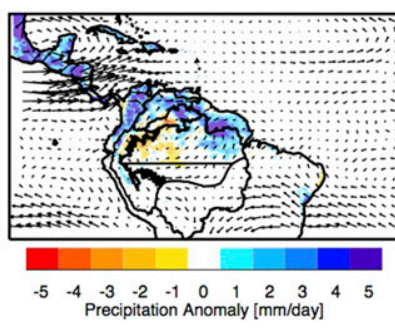

c) VSML4 February 2010

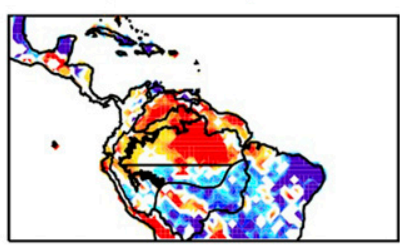

g) VSML4 April 2010

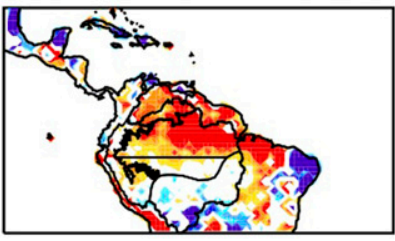

k) VSML4 June 2010

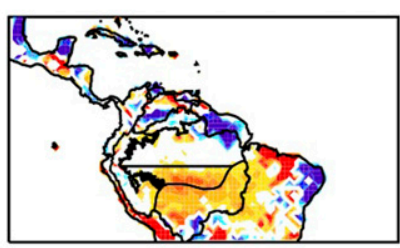

o) VSML4 August 2010

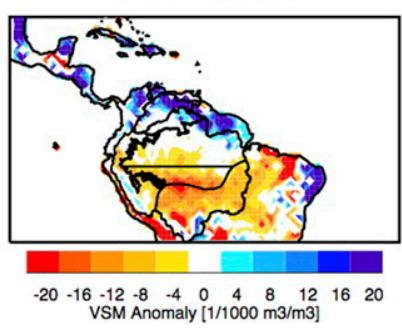

d) NDVI February 2010

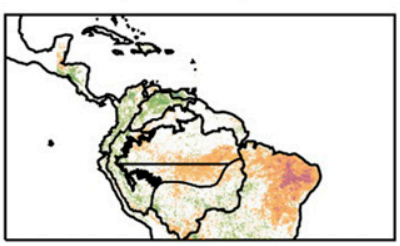

h) NDVI April 2010

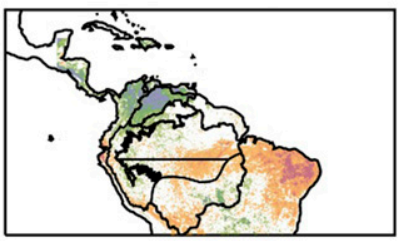

I) NDVI June 2010

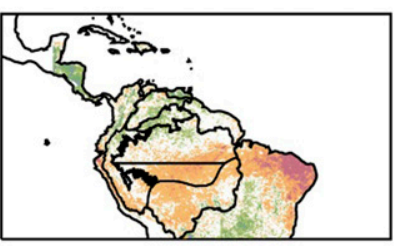

p) NDVI August 2010

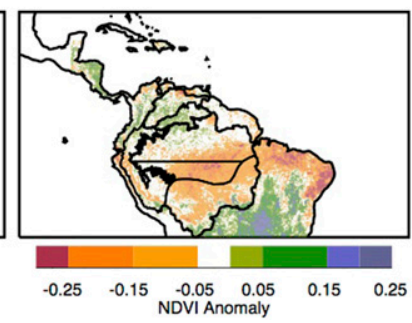

FIG. 9. Detrended anomalies of (first column) SSTs, (second column) 850-hPa winds (vectors) and precipitation (shading), (third column) ERA5 VSML4, and (fourth column) NDVI during (a)-(d) February, (e)-(h) April, (i)-(l) June, and (m)-(p) August 2010. Polygons delimit the six continental subregions of interest: northern Amazon (NAMZ), central Amazon (CAMZ), northern Orinoco (NORIC), southern Orinoco (SORIC), Arc of Deforestation (ADEF), and Andean Piedmont (PMNT) shown in Fig. 1.

moisture began to decrease until exhibiting negative anomalies from April to September (Fig. 9, third column). This deficit of soil moisture reached its most critical value over the central Amazon and the Arc of Deforestation in AugustSeptember 2010 (Fig. 9, third column). NDVI started to decline in April-June 2010, reaching minimum values in August-September, in agreement with the timeline of reductions in soil moisture (Fig. 9, third column). Negative NDVI anomalies in August-September 2010 were consistent with the reductions of moisture recycling over the central and southern Amazon observed in September 2010 (Fig. 10f). These hydrological changes were also consistent with reduced river discharge in Solimões (Espinoza et al. 2011), which reached its lowest value in September 2010.

Thus, the response of NDVI over the central Amazon and the Arc of Deforestation to the warmer CABN and TNA conditions observed during April-June 2005 and 2010 appears to have been related to a weakening in the low-level moisture transport toward the Amazon and reductions of precipitation during the first months of the year (wet season). Together, these changes caused soil moisture deficits and inhibited vegetation activity in the southernmost Amazon basin during the dry season. Changes in soil moisture depicted by ERA5 over the central Amazon and Arc of Deforestation (Fig. 7, left column) are consistent with measurements of total water storage from the GRACE satellite platform as reported by previous studies (Frappart et al. 2012; Papa et al. 2013) (Fig. 5). According to Figs. 7-10, both the central Amazon and the Arc of Deforestation are highly sensitive to changes in CABN and TNA SST changes. Precipitation over these Amazonian regions shows the fastest response to increases in SSTs, with negative anomalies emerging around 1 month after the warm anomalies in SST and the largest negative anomalies observed between April and June. Negative anomalies 
(a) From TNA 2010-03

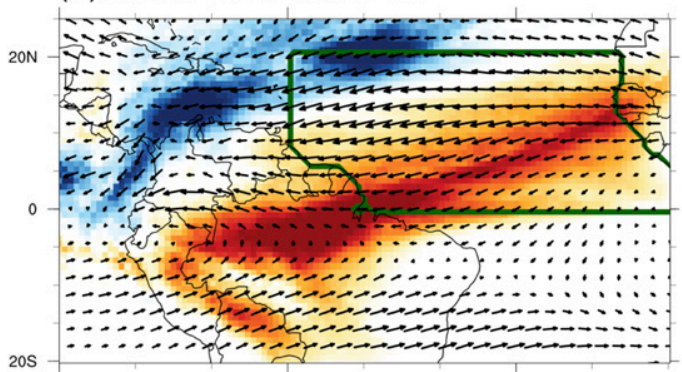

(b) From TNA 2010-04

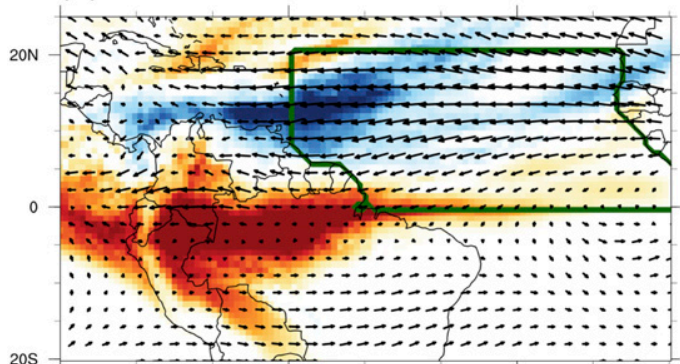

(c) From TSA 2010-04

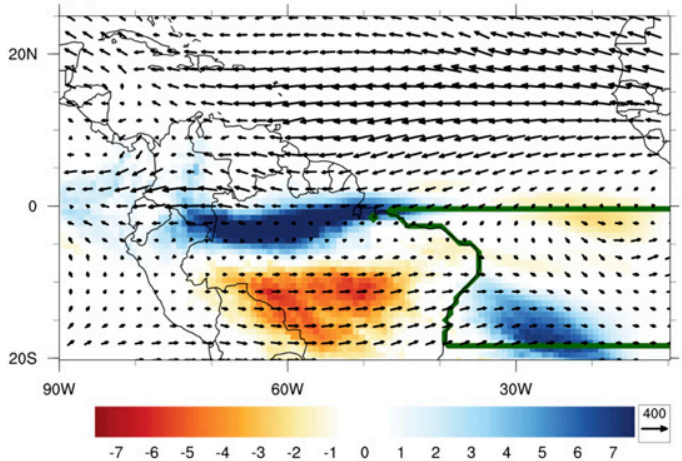

(d) From NoAmaz 2010-04

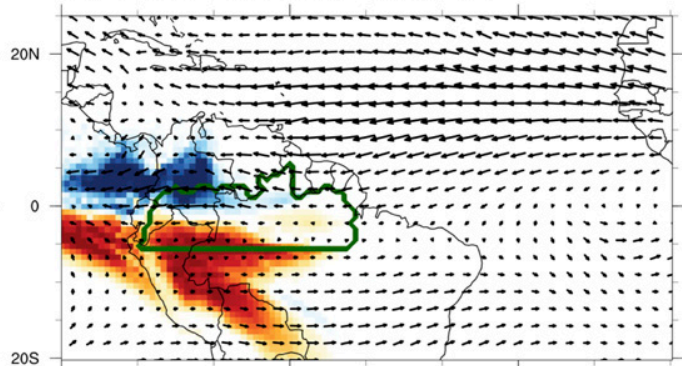

(e) From ORIC 2010-06

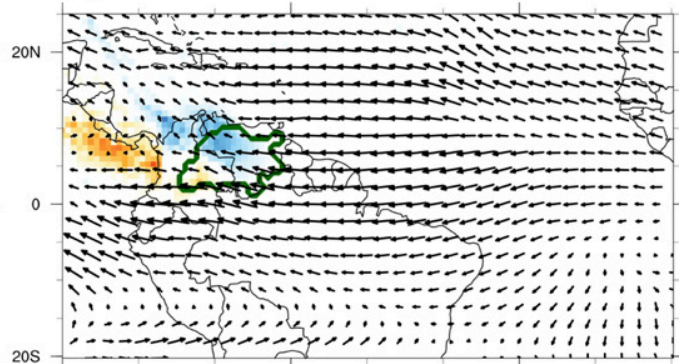

(f) From SoAmaz 2010-09

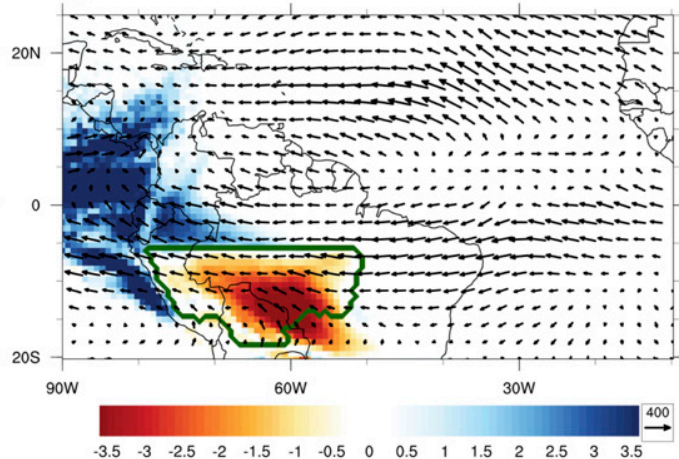

FIG. 10. Detrended anomalies of precipitable water contributions (shading, in $\mathrm{mm}$ ) from the tropical North Atlantic (TNA) during (a) March and (b) April 2010; (c) the tropical South Atlantic (TSA) during April 2010; (d) the northern Amazon (NoAmaz) during April 2010; (e) the Orinoco (ORIC) during June 2010; and (f) the southern Amazon (SoAmaz) during September 2010. Vectors indicate vertically integrated moisture flux (in $\mathrm{kg}$ $\mathrm{m}^{-1} \mathrm{~s}^{-1}$ ). Green polygons correspond to the water vapor source region considered in the corresponding DRM simulation. The TSA and TNA source regions correspond to the same domains shown in Fig. 1a. The NoAmaz and SoAmaz source regions differ from the NAMZ and CAMZ regions shown in Fig. 1. The NoAmaz includes the NAMZ and PMNT region north of $5^{\circ} \mathrm{S}$. The SoAmaz includes the CAMZ, ADEF, and PMNT region south of $5^{\circ} \mathrm{S}$.

in soil moisture also arise around 1 month after the increase of SSTs in the tropical Atlantic but show more persistence than precipitation. NDVI begins to decrease around 2 months after precipitation and soil moisture, reaching its largest negative anomalies in September over the central Amazon and the Arc of Deforestation. These changes are depicted in Fig. 11a.

\section{2) ANOMALIES IN THE NORTHERN ORINOCO}

For the northern Orinoco basin, our results indicate that 2005 started with positive anomalies of precipitation (Fig. 7, second column) and ERA5 VSML4 (Fig. 7, third column) over most of northern South America, coinciding with positive anomalies of NDVI in this region in February-April 2005 (Fig. 7, fourth column). However, these precipitation anomalies weakened during AprilAugust. The increase of precipitation over the northern Orinoco by early 2005 was related to increased atmospheric moisture convergence into the region, induced by a weakening of the northeasterly trade winds over the Atlantic (Fig. 7, second column), which enhanced water vapor transport from the TNA to this region (Fig. 8a). However, precipitation, soil moisture, and NDVI decreased in the northern Orinoco by June 2005. 


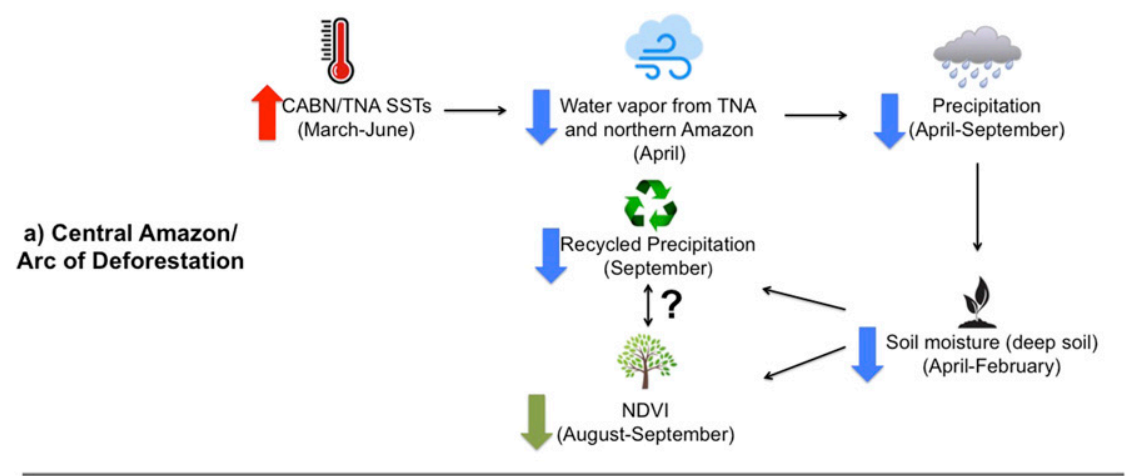

b) Northern Orinoco

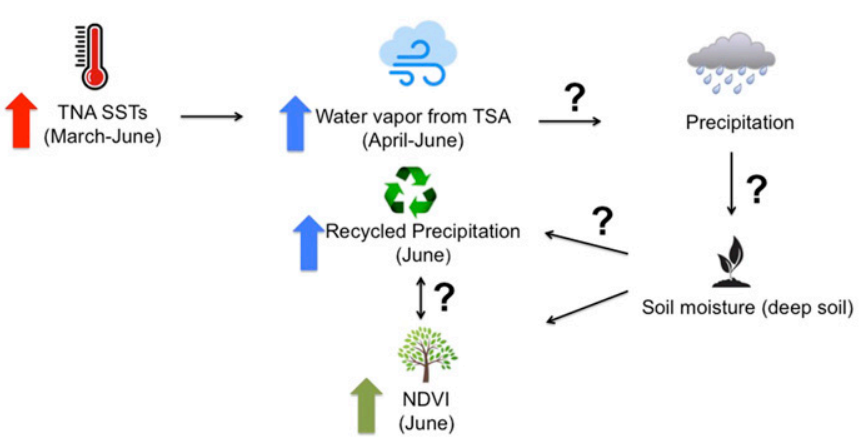

FIG. 11. Schematics of the relationship between tropical Atlantic SSTs and NDVI anomalies over (a) the central Amazon and the Arc of Deforestation, and (b) the northern Orinoco basin. Text in parentheses indicates the months with statistically significant correlations between the correspondent variable and SSTs (Figs. 3-6).

During 2010, positive precipitation anomalies were observed over northern South America from April to September (Fig. 9, second column). These anomalies were related to weaker northeasterly trade winds (Fig. 9, second column) and increased atmospheric moisture advection from the TNA, especially during MarchApril 2010 (Figs. 10a,b). The weakening of the trade winds was in turn associated with a weaker Caribbean LLJ (CALLJ), which, in addition to a stronger Chocó LLJ (as reported by Arias et al. 2015b), generated large amounts of precipitation over northern South America during 2010 (Arias et al. 2015b). These changes in atmospheric moisture transport were consistent with positive precipitation anomalies observed over the northern Orinoco from April to September 2010 (Fig. 9, second column).

According to ERA5 soil moisture at the deepest layers, the corresponding positive anomalies emerged during the following months (June-August 2010) (Fig. 9, third column), showing a recovery of negative anomalies that were inherited from late 2009. These deficits were associated with the cumulative effects of the 2009/10 El Niño event, which reduced precipitation over northern South America in late 2009 and early 2010 (Arias et al. 2015b), probably reducing soil moisture in the northern
Orinoco during the first months of 2010. NDVI showed its largest positive anomalies during April 2010, when positive precipitation anomalies and negative soil moisture anomalies were observed in the northern Orinoco (Fig. 9). By June-August 2010, NDVI showed a reduction, although still exhibiting positive anomalies (Fig. 9, fourth column). Moreover, moisture recycling was enhanced during June 2010 in the northern Orinoco (Fig. 10e). This is in sharp contrast with the general decrease in moisture recycling over large parts of the Amazon, as described above (see Figs. 8 and 10).

\section{Summary and conclusions}

Vegetation activity measured by the normalized difference vegetation index (NDVI) in the central Amazon and the Arc of Deforestation shows maximum variability during the local dry season (August-September). Our results suggest that negative NDVI anomalies over these regions occur in association with precedent warm anomalies in SSTs over the tropical North Atlantic (TNA) and the Caribbean Sea (CABN) between March and June. In particular, an anomalous warming of these oceanic regions induces changes in surface winds and atmospheric moisture transport in the region. These 
changes in the circulation reduce precipitation in the central Amazon and the Arc of Deforestation, leading in turn to decreases in soil moisture and vegetation activity (NDVI and precipitation recycling) over both regions (Fig. 11a). On the other hand, for the northern Orinoco, we identify that an increase of the SSTs over the TNA and CABN during the months of March to June is associated with an increase of NDVI during the local wet season (June). Precipitation and soil moisture do not exhibit a clear link with TNA SSTs and NDVI; however, moisture recycling in the northern Orinoco basin is enhanced during June when TNA SSTs are warmer in March-June (Fig. 11b); in contrast, moisture recycling decreases over the southern Amazon in relation to higher SSTs in parts of the tropical Atlantic. Thus, our results suggest the existence of an interesting relationship between SSTs in the Atlantic, and moisture recycling and enhanced NDVI over the northern Orinoco. The causality of this relationship needs to be further explored. In particular, we require further research to understand the land-atmosphere interactions in the Orinoco basin, for instance the role of surface energy fluxes and their influence on cloudiness and fire activity in surrounding regions.

Our results suggest elements that link changes in surface temperatures in the tropical Atlantic Ocean with changes in the atmospheric circulation over South America, affecting vegetation over two key basins in the region, although more detailed studies are required to understand the mechanisms connecting SSTAs and NDVI in the Orinoco basin. In fact, studies focused on the Orinoco River basin are relatively scarce (compared to the Amazon). This work thus provides new elements that can contribute to a better understanding of the hydrological cycle in this basin.

Vegetation in these basins shows contrasting responses to a warming of the tropical North Atlantic. Warmer conditions over the tropical Atlantic favor enhanced vegetation activity over the northern Orinoco but reduced vegetation activity in the central Amazon and the Arc of Deforestation. The weakening of the northeasterly trade winds over the Atlantic, as well as the Caribbean and South American low-level jets explains the changes in atmospheric moisture transport over South America. Such changes in the low-level circulation enhance atmospheric moisture divergence over the southern Amazon (Figs. 8 and 10). This is related with the anomalous northward displacement of the Atlantic ITCZ that induces a meridionally divergent circulation over the southern Amazon basin, and is caused by increased temperature gradient between the northern and southern tropical Atlantic. This anomalous divergence results in anomalous descending motion over the southern Amazon, which inhibits both atmospheric moisture transport from the TNA and moisture recycling over the central Amazon and the Arc of Deforestation (Figs. 6, 8, and 10). These anomalies result in rainfall deficits over these regions. This is evident in Figs. 7 and 9 (second column), especially during April-June 2010, when precipitation, soil moisture, and NDVI begin to experience negative anomalies over the central and southern Amazon. As a response to these changes in regional circulation and atmospheric moisture transport, northern South America (and the northern Orinoco) exhibits enhanced water vapor transport and precipitation, as observed in 2010; however, NDVI does not exhibit a clear response to these changes in precipitation and soil moisture (Fig. 9).

These contrasting changes between northern South America and the central and southern Amazon have been observed in precipitation (Espinoza et al. 2019a; Fu et al. 2013; Wang et al. 2018) and streamflow in the main tributaries of the Amazon River (Barichivich et al. 2018; Espinoza et al. 2009a; Molina-Carpio et al. 2017), particularly in association with warmer conditions over the TNA and CABN (Wang et al. 2018). Furthermore, the analysis of climate projections for the southern Amazon suggests that the dry season in this region could become longer (Boisier et al. 2015), which would impose greater moisture stress on the Amazon forest.

In summary, our study suggests that positive SST anomalies in the CABN and the TNA during MarchJune are followed by anomalous surface winds over tropical South America (associated with reduced advection of moist air toward the southern Amazon). These changes occur about 1 month after the SST anomalies. Soil moisture in the central Amazon and the Arc of Deforestation responds approximately 1-2 months after the ocean warming, but NDVI exhibits a more delayed response with lags between 2 and 5 months with respect to SSTs, and a maximum response during August-September (transition from the dry to wet season). In the northern Orinoco, warmer TNA SSTs in March-June are not significantly correlated with precipitation or soil moisture, but are correlated with NDVI, with the strongest positive correlation during June (wet season) and increased moisture recycling. Figure 11 shows a schematic synthesis of these features. One important consequence is that increases of NDVI in the Orinoco are mainly observed during the local wet season, whereas reductions in soil moisture and NDVI in the central and southern Amazon are observed during the transition from dry to wet conditions. The latter may be particularly important in light of indications that the dry season in the southern Amazon has lengthened over the last three decades (Arias et al. 2015a; Debortoli et al. 2015; 
Fu et al. 2013), which could impose enhanced water stress on Amazonian ecosystems. On the other hand, further studies are required in order to understand the mechanisms behind the response of NDVI in the northern Orinoco. Although precipitation and soil moisture in this region do not appear to be linked to SST changes, the response of atmospheric moisture transport and recycling in the northern Orinoco could be behind the mechanisms inducing the response of vegetation in the Orinoco basin.

Acknowledgments. This work was founded by Universidad de Antioquia through the Grant CODI PRG2017-16264. J. C. Espinoza and S. Wongchuig-Correa were supported by the AMANECER (Amazon-Andes Connectivity) Project-Make Our Planet Great Again Program, funded by ANR and IRD (ANR-18-MPGA-0008). We acknowledge Melissa Ruiz-Vásquez for providing Fig. 1. We are also thankful for the insightful comments from three anonymous reviewers and the Editor. The authors indicate no conflict of interests.

\section{REFERENCES}

Agudelo, J., P. A. Arias, S. C. Vieira, and J. A. Martínez, 2018: Influence of longer dry seasons in the southern Amazon on patterns of water vapor transport over northern South America and the Caribbean. Climate Dyn., 52, 2647-2665, https://doi.org/10.1007/s00382-018-4285-1.

Aguiar, A. P. D., and Coauthors, 2016: Land use change emission scenarios: Anticipating a forest transition process in the Brazilian Amazon. Global Change Biol., 22, 1821-1840, https:// doi.org/10.1111/gcb.13134.

Ampuero, A., and Coauthors, 2020: The forest effects on the isotopic composition of rainfall in the northwestern Amazon Basin. J. Geophys. Res. Atmos., 125, e2019JD031445, https:// doi.org/10.1029/2019JD031445.

Arias, P. A., R. Fu, C. D. Hoyos, W. Li, and L. Zhou, 2011: Changes in cloudiness over the Amazon rainforests during the last two decades: Diagnostic and potential causes. Climate Dyn., 37, 1151-1164, https://doi.org/10.1007/s00382-010-0903-2.

$\longrightarrow, \ldots$, C. Vera, and M. Rojas, 2015a: A correlated shortening of the North and South American monsoon seasons in the past few decades. Climate Dyn., 45, 3183-3203, https://doi.org/ 10.1007/s00382-015-2533-1.

— J. A. Martínez, and S. C. Vieira, 2015b: Moisture sources to the 2010-2012 anomalous wet season in northern South America. Climate Dyn., 45, 2861-2884, https://doi.org/10.1007/ s00382-015-2511-7.

Ashouri, H., K.-L. Hsu, S. Sorooshian, D. K. Braithwaite, K. R. Knapp, L. Dewayne Cecil, B. R. Nelson, and O. P. Prat, 2015: PERSIANN-CDR: Daily precipitation climate data record from multisatellite observations for hydrological and climate studies. Bull. Amer. Meteor. Soc., 96, 69-83, https://doi.org/ 10.1175/BAMS-D-13-00068.1.

Barichivich, J., E. Gloor, P. Peylin, R. J. W. Brienen, J. Schöngart, J. C. Espinoza, and K. C. Pattnayak, 2018: Recent intensification of Amazon flooding extremes driven by strengthened
Walker circulation. Sci. Adv., 4, eaat8785, https://doi.org/ 10.1126/sciadv.aat8785.

Boers, N., N. Marwan, H. M. J. Barbosa, and J. Kurths, 2017: A deforestation-induced tipping point for the South American monsoon system. Sci. Rep., 7, 41489, https://doi.org/10.1038/ srep41489.

Boisier, J. P., P. Ciais, A. Ducharne, and M. Guimberteau, 2015: Projected strengthening of Amazonian dry season by constrained climate model simulations. Nat. Climate Change, $\mathbf{5}$, 656-660, https://doi.org/10.1038/nclimate2658.

Boussetta, S., G. Balsamo, A. Beljaars, T. Kral, and L. Jarlan, 2013: Impact of a satellite-derived leaf area index monthly climatology in a global numerical weather prediction model. Int. J. Remote Sens., 34, 3520-3542, https://doi.org/10.1080/ 01431161.2012.716543.

Builes-Jaramillo, A., N. Marwan, G. Poveda, and J. Kurths, 2018: Nonlinear interactions between the Amazon River basin and the tropical North Atlantic at interannual timescales. Climate Dyn., 50, 2951-2969, https://doi.org/10.1007/s00382-017-3785-8.

Burde, G., and A. Zangvil, 2001: The estimation of regional precipitation recycling. Part I : Review of recycling models. J. Climate, 14, 2497-2508, https://doi.org/10.1175/1520-0442(2001)014<2497: TEORPR $>2.0 . \mathrm{CO} ; 2$.

Cao, B., S. Gruber, D. Zheng, and X. Li, 2020: The ERA5-land soiltemperature bias in permafrost regions. Cryosphere Discuss., https://doi.org/10.5194/tc-2020-76.

Chen, J. L., C. R. Wilson, and B. D. Tapley, 2010: The 2009 exceptional Amazon flood and interannual terrestrial water storage change observed by GRACE. Water Resour. Res., 46 (12), 1-10, https://doi.org/10.1029/2010WR009383.

Coe, M. T., and Coauthors, 2013: Deforestation and climate feedbacks threaten the ecological integrity of south-southeastern Amazonia. Philos. Trans. Roy. Soc. London, B368, 20120155, https://doi.org/10.1098/RSTB.2012.0155.

Coelho, C. A. S., and Coauthors, 2012: Climate diagnostics of three major drought events in the Amazon and illustrations of their seasonal precipitation predictions. Meteor. Appl., 19, 237-255, https://doi.org/10.1002/met.1324.

Copernicus Climate Change Service, 2019: C3S ERA5-Land reanalysis. Copernicus Climate Change Service. Accessed 27 May 2020, https://cds.climate.copernicus.eu/cdsapp\#!/dataset/reanalysisera5-land?tab $=$ form.

Costa, M. H., and J. A. Foley, 1999: Trends in the hydrologic cycle of the Amazon basin. J. Geophys. Res., 104, 14 189-14 198, https://doi.org/10.1029/1998JD200126.

_ deforestation scenarios on the duration of the dry season in the arc of deforestation. Int. J. Climatol., 30, 1970-1979, https:// doi.org/10.1002/joc.2048.

da Rocha, H. R., M. L. Goulden, S. D. Miller, M. C. Menton, L. D. V. O. Pinto, H. C. de Freitas, and A. M. e Silva Figueira, 2004: Seasonality of water and heat fluxes over a tropical forest in eastern Amazonia. Ecol. Appl., 14 (Suppl. 4), 22-32, https:// doi.org/10.1890/02-6001.

Davidson, E. A., and Coauthors, 2012: The Amazon basin in transition. Nature, 481, 321-328, https://doi.org/10.1038/nature10717.

Debortoli, N., V. Dubreuil, B. M. Funatsu, F. Delahaye, C. H. de Oliveira, S. Rodrigues-Filho, C. H. Saito, and R. Fetter, 2015: Rainfall patterns in the southern Amazon: A chronological perspective (1970-2010). Climatic Change, 132, 251-269, https:// doi.org/10.1007/S10584-015-1415-1.

Dee, D. P., and Coauthors, 2011: The ERA-Interim reanalysis: Configuration and performance of the data assimilation sys- 
tem. Quart. J. Roy. Meteor. Soc., 137, 553-597, https://doi.org/ 10.1002/qj.828.

de Rosnay, P., M. Drusch, D. Vasiljevic, G. Balsamo, C. Albergel, and L. Isaksen, 2013: A simplified extended Kalman filter for the global operational soil moisture analysis at ECMWF. Quart. J. Roy. Meteor. Soc., 139, 1199-1213, https://doi.org/ 10.1002/qj.2023.

Efron, B., 1992: Bootstrap methods: Another look at the jackknife. Breakthroughs in Statistics, S. Kotz and N. L. Johnson, Springer, 569-593, https://doi.org/10.1007/978-1-4612-4380-9_ 41.

Eltahir, E. A. B., and R. L. Bras, 1996: Precipitation recycling. Rev. Geophys., 34, 367-378, https://doi.org/10.1029/96RG01927.

Erfanian, A., G. Wang, and L. Fomenko, 2017: Unprecedented drought over tropical South America in 2016: Significantly under-predicted by tropical SST. Sci. Rep., 7, 5811, https:// doi.org/10.1038/s41598-017-05373-2.

Espinoza, J. C., and Coauthors, 2009a: Contrasting regional discharge evolutions in the Amazon basin (1974-2004). J. Hydrol., 375, 297-311, https://doi.org/10.1016/j.jhydrol.2009.03.004.

_ , and Coauthors, 2009b: Spatio-temporal rainfall variability in the Amazon basin countries (Brazil, Peru, Bolivia, Colombia, and Ecuador). Int. J. Climatol., 29, 1574-1594, https://doi.org/ 10.1002/joc. 1791

_ - and Coauthors, 2011: Climate variability and extreme drought in the upper Solimões River (western Amazon Basin): Understanding the exceptional 2010 drought. Geophys. Res. Lett., 38, L13406, https://doi.org/10.1029/2011GL047862.

—, S. Chavez, J. Ronchail, C. Junquas, K. Takahashi, and W. Lavado, 2015: Rainfall hotspots over the southern tropical Andes: Spatial distribution, rainfall intensity, and relations with large-scale atmospheric circulation. Water Resour. Res., 51, 3459-3475, https://doi.org/10.1002/2014WR016273.

-, H. Segura, J. Ronchail, G. Drapeau, and O. Gutierrez-Cori, 2016: Evolution of wet-day and dry-day frequency in the western Amazon basin: Relationship with atmospheric circulation and impacts on vegetation. Water Resour. Res., 52, 8546-8560, https://doi.org/10.1002/2016WR019305.

_, J. Ronchail, J. A. Marengo, and H. Segura, 2019a: Contrasting north-south changes in Amazon wet-day and dry-day frequency and related atmospheric features (1981-2017). Climate Dyn., 52, 5413-5430, https://doi.org/10.1007/s00382-018-4462-2.

_- and Coauthors, 2019b: Regional hydro-climatic changes in the southern Amazon Basin (upper Madeira Basin) during the 1982-2017 period. J. Hydrol. Reg. Stud., 26, 100637, https:// doi.org/10.1016/j.ejrh.2019.100637.

—, R. Garreaud, G. Poveda, P. A. Arias, J. Molina-Carpio, M. Masiokas, M. Viale, and L. Scaff, 2020: Hydroclimate of the Andes. Part I: Main climatic features. Front. Earth Sci., 8, 64, https://doi.org/10.3389/feart.2020.00064.

Fearnside, P. M., and P. M. L. de Alencastro Graca, 2006: BR-319: Brazil's Manaus-Porto Velho highway and the potential impact of linking the Arc of Deforestation to central Amazonia. Environ. Manage, 38, 705-716, https://doi.org/10.1007/S00267005-0295-Y.

Fernandes, K., and Coauthors, 2011: North tropical Atlantic influence on western Amazon fire season variability. Geophys. Res. Lett., 38, L12701, https://doi.org/10.1029/2011GL047392.

Frappart, F., F. Papa, J. S. da Silva, G. Ramillien, C. Prigent, F. Seyler, and S. Calmant, 2012: Surface freshwater storage and dynamics in the Amazon basin during the 2005 exceptional drought. Environ. Res. Lett., 7, 044010, https://doi.org/10.1088/ 1748-9326/7/4/044010.
— G. Ramillien, and J. Ronchail, 2013: Changes in terrestrial water storage versus rainfall and discharges in the Amazon basin. Int. J. Climatol., 33, 3029-3046, https://doi.org/10.1002/ joc.3647.

$\mathrm{Fu}, \mathrm{R}$., and W. Li, 2004: The influence of the land surface on the transition from dry to wet season in Amazonia. Theor. Appl. Climatol., 78, 97-110, https://doi.org/10.1007/S00704-004-0046-7. , and Coauthors, 2013: Increased dry-season length over southern Amazonia in recent decades and its implication for future climate projection. Proc. Natl. Acad. Sci. USA, 110, 18110-18115, https://doi.org/10.1073/pnas.1302584110.

Funk, C., and Coauthors, 2015: The Climate Hazards Infrared Precipitation with Stations-A new environmental record for monitoring extremes. Sci. Data, 2, 150066, https://doi.org/ 10.1038/SDATA.2015.66.

Getirana, A. C. V., and Coauthors, 2011: Calibração e validação de modelo hidrológico com observações in situ, altimetria e gravimetria espaciais [Calibration and validation of a hydrological model with in situ observations, spatial altimetry and gravimetry]. Rev. Bras. Recur. Hidricos, 16, 29-45, https:// doi.org/10.21168/RBRH.V16N1.P29-45.

Herrera-Estrada, J. E., J. A. Martinez, F. Dominguez, K. L. Findell, E. F. Wood, and J. Sheffield, 2019: Reduced moisture transport linked to drought propagation across North America. Geophys. Res. Lett., 46, 5243-5253, https://doi.org/10.1029/ 2019GL082475.

Hersbach, H., and D. Dee, 2016: ERA5 reanalysis is in production. ECMWF Newsletter, No. 147, ECMWF, Reading, United Kingdom, 7, http://www.ecmwf.int/sites/default/files/elibrary/ 2016/16299-newsletter-no147-spring-2016.pdf.

, and Coauthors, 2020: The ERA5 global reanalysis. Quart. J. Roy. Meteor. Soc., 146, 1999-2049, https://doi.org/10.1002/ qj.3803.

Hilker, T., and Coauthors, 2014: Vegetation dynamics and rainfall sensitivity of the Amazon. Proc. Natl. Acad. Sci. USA, 111, 16 041-16 046, https://doi.org/10.1073/pnas.1404870111.

Hodnett, M. G., M. D. Oyama, J. Tomasella, and A. O. M. Filho, 1996: Comparisons of long-term soil water storage behavior under pasture and forest in three areas of Amazonia. Amazonian Deforestation and Climate, G. H. Gash, Ed., John Wiley \& Sons, 57-77.

Hoyos, I., J. Cañón-Barriga, T. Arenas-Suárez, F. Dominguez, and B. A. Rodríguez, 2019: Variability of regional atmospheric moisture over northern South America: Patterns and underlying phenomena. Climate Dyn., 52, 893-911, https://doi.org/ 10.1007/S00382-018-4172-9.

Hoyos, N., J. Escobar, J. C. Restrepo, A. M. Arango, and J. C. Ortiz, 2013: Impact of the 2010-2011 La Niña phenomenon in Colombia, South America: The human toll of an extreme weather event. Appl. Geogr., 39, 16-25, https://doi.org/ 10.1016/j.apgeog.2012.11.018.

Huete, A. R., and Coauthors, 2006: Amazon rainforests green-up with sunlight in dry season. Geophys. Res. Lett., 33, L06405, https://doi.org/10.1029/2005GL025583.

Huffman, G. J., and Coauthors, 1997: The Global Precipitation Climatology Project (GPCP) combined precipitation dataset. Bull. Amer. Meteor. Soc., 78, 5-20, https://doi.org/10.1175/ 1520-0477(1997)078<0005:TGPCPG > 2.0.CO;2.

Jiménez-Sánchez, G., P. M. Markowski V. Jewtoukoff, G. S. Young, and D. J. Stensrud, 2019: The Orinoco low-level jet: An investigation of its characteristics and evolution using the WRF model. J. Geophys. Res. Atmos., 124, 10 696-10711, https://doi.org/10.1029/2019JD030934. 
Jones, C., 2019: Recent changes in the South America low-level jet. Climate Atmos. Sci., 2, 20, https://doi.org/10.1038/S41612-0190077-5.

Labat, D., J. C. Espinoza, J. Ronchail, G. Cochonneau, E. de Oliveira, J. C. Doudou, and J.-L. Guyot, 2012: Fluctuations in the monthly discharge of Guyana shield rivers, related to Pacific and Atlantic climate variability. Hydrol. Sci. J., 57, 1081-1091, https://doi.org/10.1080/02626667.2012.695074.

Lewis, S. L., P. M. Brando, O. L. Phillips, G. M. F. van der Heijden, and D. Nepstad, 2011: The 2010 Amazon drought. Science, 331, 554, https://doi.org/10.1126/science.1200807.

Li, W., and R. Fu, 2004: Transition of the large-scale atmospheric and land surface conditions from the dry to the wet season over Amazonia as diagnosed by the ECMWF re-analysis. J. Climate, 17, 2637-2651, https://doi.org/10.1175/1520-0442(2004) 017<2637:TOTLAA $>2.0$.CO;2.

Maeda, E. E., H. Kim, L. E. O. C. Aragão, J. S. Famiglietti, and T. Oki, 2015: Disruption of hydroecological equilibrium in southwest Amazon mediated by drought. Geophys. Res. Lett., 42, 7546-7553, https://doi.org/10.1002/2015GL065252.

Marengo, J. A., 2005: Characteristics and spatio-temporal variability of the Amazon River Basin water budget. Climate Dyn., 24, 11-22, https://doi.org/10.1007/s00382-004-0461-6.

- 2006 : On the hydrological cycle of the Amazon Basin: A historical review and current state-of-the-art Jose Antonio Marengo Centro de Previsão de Tempo e Estudos Climáticos do Instituto Nacional de Pesquisas Espaciais (CPTEC/INPE). Rev. Bras. Meteor., 21, 1-19.

— floods in Amazonia: Causes, trends and impacts. Int. J. Climatol., 36, 1033-1050, https://doi.org/10.1002/joc.4420.

—, C. J. T. Nobre, M. F. Cardoso, and M. D. Oyama, 2008: Hydro-climatic and ecological behaviour of the drought of Amazonia in 2005. Philos. Trans. Roy. Soc. London, B363, 1773-1778, https://doi.org/10.1098/RSTB.2007.0015.

— , J. Tomasella, L. M. Alves, W. R. Soares, and D. A. Rodriguez, 2011: The drought of 2010 in the context of historical droughts in the Amazon region. Geophys. Res. Lett., 38, L12703, https://doi.org/10.1029/2011GL047436.

Martinez, J. A., and F. Dominguez, 2014: Sources of atmospheric moisture for the La Plata River Basin. J. Climate, 27, 67376753, https://doi.org/10.1175/JCLI-D-14-00022.1.

Molina, R. D., J. F. Salazar, J. A. Martínez, J. C. Villegas, and P. A. Arias, 2019: Forest-induced exponential growth of precipitation along climatological wind streamlines over the Amazon. J. Geophys. Res. Atmos., 124, 2589-2599, https://doi.org/ 10.1029/2018JD029534.

Molina-Carpio, J., J. C. Espinoza, P. Vauchel, J. Ronchail, B. G. Caloir, J.-L. Guyot, and L. Noriega, 2017: Hydroclimatology of the Upper Madeira River basin: Spatio-temporal variability and trends. Hydrol. Sci. J., 62, 911-927, https://doi.org/10.1080/ 02626667.2016.1267861.

Montini, T. L., C. Jones, and L. M. V. Carvalho, 2019: The South American low-level jet: A new climatology, variability, and changes. J. Geophys. Res. Atmos., 124, 1200-1218, https:// doi.org/10.1029/2018JD029634.

Morton, D. C., and Coauthors, 2014: Amazon forests maintain consistent canopy structure and greenness during the dry season. Nature, 506, 221-224, https://doi.org/10.1038/nature13006.

Nieto, R., D. Gallego, R. Trigo, P. Ribera, and L. Gimeno, 2008: Dynamic identification of moisture sources in the Orinoco basin in equatorial South America. Hydrol. Sci. J., 53, 602-617, https://doi.org/10.1623/hysj.53.3.602.
Nobre, C. A., G. O. Obregón, J. A. Marengo, and G. Poveda, 2009: Characteristics of Amazonian climate: Main features. Amazonia and Global Change, Geophys. Monogr., Vol. 186, Amer. Geophys. Union, 149-162.

Panisset, J. S., R. Libonati, C. M. P. Gouveia, F. Machado-Silva, D. A. França, J. R. A. França, and L. F. Peres, 2018: Contrasting patterns of the extreme drought episodes of 2005, 2010 and 2015 in the Amazon Basin. Int. J. Climatol., 38, 10961104, https://doi.org/10.1002/JOC.5224.

Papa, F., A. Gu, F. Frappart, C. Prigent, and W. B. Rossow, 2008: Variations of surface water extent and water storage in large river basins: A comparison of different global data sources. Geophys. Res. Lett., 35, L11401, https://doi.org/10.1029/2008GL033857.

— , F. Frappart, A. Gu, C. Prigent, F. Aires, A. C. V. Getirana, and R. Maurer, 2013: Surface freshwater storage and variability in the Amazon basin from multi-satellite observations, 1993-2007. J. Geophys. Res. Atmos., 118, 11951-11965, https://doi.org/10.1002/2013JD020500.

Poveda, G., and O. J. Mesa, 1997: Feedbacks between hydrological processes in tropical South America and large-scale oceanatmospheric phenomena. J. Climate, 10, 2690-2702, https:// doi.org/10.1175/1520-0442(1997)010<2690:FBHPIT>2.0. $\mathrm{CO} ; 2$.

_ P. R. Waylen, and R. S. Pulwarty, 2006: Annual and interannual variability of the present climate in northern South America and southern Mesoamerica. Palaeogeogr. Palaeoclimatol. Palaeoecol., 234, 3-27, https://doi.org/10.1016/j.palaeo.2005. 10.031.

Ramillien, G., J. S. Familglietti, and J. Wahr, 2008: Detection of continental hydrology and glaciology signals from GRACE: A review. Surv. Geophys., 29, 361-374, https://doi.org/10.1007/ s10712-008-9048-9.

Restrepo-Coupe, N., and Coauthors, 2013: What drives the seasonality of photosynthesis across the Amazon basin? A crosssite analysis of eddy flux tower measurements from the Brasil flux network. Agric. For. Meteor., 182-183, 128-144, https:// doi.org/10.1016/j.agrformet.2013.04.031.

Reynolds, R. W., N. A. Rayner, T. M. Smith, D. C. Stokes, and W. Wang, 2002: An improved in situ and satellite SST analysis for climate. J. Climate, 15, 1609-1625, https://doi.org/10.1175/ 1520-0442(2002)015<1609:AIISAS > 2.0.CO;2.

Roy, T., and Coauthors, 2019: Role of moisture transport and recycling in characterizing droughts: Perspectives from two recent U.S. droughts and the CFSv2 system. J. Climate, 20, 139-154, https://doi.org/10.1175/JHM-D-18-0159.1.

Ruiz-Vásquez, M., P. A. Arias, J. A. Martinez, and J. C. Espinoza, 2020: Effects of Amazon basin deforestation on regional atmospheric circulation and water vapor transport towards tropical South America. Climate Dyn., 54, 4169-4189, https:// doi.org/10.1007/s00382-020-05223-4.

Saatchi, S., S. Asefi-Najafabady, Y. Malhi, L. E. O. C. Aragao, L. O. Anderson, R. B. Myneni, and R. Nemani, 2013: Persistent effects of a severe drought on Amazonian forest canopy. Proc. Natl. Acad. Sci. USA, 110, 565-570, https:// doi.org/10.1073/pnas.1204651110.

Sakamoto, M. S., T. Ambrizzi, and G. Poveda, 2011: Moisture sources and life cycle of convective systems over western Colombia. Adv. Meteor., 2011, 1-11, https://doi.org/10.1155/ 2011/890759.

Saleska, S. R., J. Wu, K. Guan, A. C. Araujo, A. Huete, A. D. Nobre, and N. Restrepo-Coupe, 2016: Dry-season greening of Amazon forests. Nature, 531, E4-E5, https://doi.org/10.1038/ NATURE16457. 
Satyamurty, P., and C. Priscila, 2013: Moisture source for the Amazon Basin: A study of contrasting years. Theor. Appl. Climatol., 111, 195-209, https://doi.org/10.1007/s00704-012-0637-7.

Siqueira, V. A., R. C. D. Paiva, A. S. Fleischmann, F. M. Fan, and A. L. Ruhoff, 2018: Toward continental hydrologic-hydrodynamic modeling in South America. Hydrol. Earth Syst. Sci., 22, 48154842, https://doi.org/10.5194/hess-22-4815-2018.

Spracklen, D. V., and L. Garcia-Carreras, 2015: The impact of Amazonian deforestation on Amazon basin rainfall. Geophys. Res. Lett., 42, 9546-9552, https://doi.org/10.1002/2015GL066063.

Staal, A., O. A. Tuinenburg, J. H. C. Bosmans, M. Holmgren, E. H van Nes, M. Scheffer, D. C. Zemp, and S. C. Dekker, 2018: Forest-rainfall cascades buffer against drought across the Amazon. Nat. Climate Change, 8, 539-543, https://doi.org/ 10.1038/s41558-018-0177-y.

Swann, A. L. S., M. Longo, R. G. Knox, E. Lee, and P. R. Moorcroft, 2015: Future deforestation in the Amazon and consequences for South American climate. Agric. For. Meteor., 214-215, 12-24, https://doi.org/10.1016/j.agrformet.2015.07.006.

Swenson, S., and J. Wahr, 2006: Post-processing removal of correlated errors in GRACE data. Geophys. Res. Lett., 33, L08402, https://doi.org/10.1029/2005GL025285.

Tapley, B. D., S. Bettadpur, J. C. Ries, P. F. Thompson, and M. M. Watkins, 2004: GRACE measurements of mass variability in the Earth system. Science, 305, 503-505, https://doi.org/ 10.1126/science. 1099192.

Torrealba, E. R., and J. Amador, 2010: La corriente en chorro de bajo nivel sobre los Llanos Venezolanos de Sur América [The low-level jet over the Venezuelan Llanos in South America]. Rev. Climatol., 10, 1-20.

Trenberth, K. E., and J. T. Fasullo, 2012: Climate extremes and climate change: The Russian heat wave and other climate extremes of 2010. J. Geophys. Res., 117, D17103, https:// doi.org/10.1029/2012JD018020.

Vera, C., and Coauthors, 2006a: Toward a unified view of the American monsoon systems. J. Climate, 19, 4977-5000, https:// doi.org/10.1175/JCLI3896.1.

— , and Coauthors, 2006b: The South American Low-Level Jet Experiment. Bull. Amer. Meteor. Soc., 87, 63-78, https:// doi.org/10.1175/BAMS-87-1-63.

Vernekar, A. D., B. P. Kirtman, and M. J. Fenessy, 2003: Low-level jets and their effects on the South American summer climate as simulated by the NCEP Eta model. J. Climate, 16, 297-311,
https://doi.org/10.1175/1520-0442(2003)016<0297:LLJATE > 2.0.CO;2.

Wagner, F. H., and Coauthors, 2017: Climate drivers of the Amazon forest greening. PLOS ONE, 12, e0180932, https:// doi.org/10.1371/journal.pone.0180932.

Wang, X., X. Li, J. Zhu, and C. A. S. Tanajura, 2018: The strengthening of Amazonian precipitation during the wet season driven by tropical sea surface temperature forcing. Environ. Res. Lett., 13, 094015, https://doi.org/10.1088/17489326/AADBB9.

Wright, J. S., R. Fu, J. R. Worden, S. Chakraborty, N. E. Clinton, C. Risi, Y. Sun, and L. Yin, 2017: Rainforest-initiated wet season onset over the southern Amazon. Proc. Natl. Acad. Sci. USA, 114, 8481-8486, https://doi.org/10.1073/pnas.1621516114.

Xavier, L., M. Becker, A. Cazenave, L. Longuevergne, W. Llovel, and O. C. R. Filho, 2010: Interannual variability in water storage over 2003-2008 in the Amazon Basin from GRACE space gravimetry, in situ river level and precipitation data. Remote Sens. Environ., 114, 1629-1637, https://doi.org/10.1016/ j.rse.2010.02.005

Xie, S., and J. A. Carton, 2004: Tropical Atlantic variability: Patterns, mechanisms, and impacts. Earth's Climate: The Ocean-Atmosphere Interaction. Geophys. Monogr., Vol. 147, Amer. Geophys. Union, 121-142.

Yin, L., R. Fu, Y.-F. Zhang, P. A. Arias, D. N. Fernando, W. Li, K. Fernandes, and A. R. Bowerman, 2014: What controls the interannual variation of the wet season onsets over the Amazon? J. Geophys. Res. Atmos., 119, 2314-2328, https:// doi.org/10.1002/2013JD021349.

Yoon, J.-H., and N. Zeng, 2010: An Atlantic influence on Amazon rainfall. Climate Dyn., 34, 249-264, https://doi.org/10.1007/ s00382-009-0551-6.

Zemp, D. C., and Coauthors, 2017: Self-amplified Amazon forest loss due to vegetation-atmosphere feedbacks. Nat. Commun., 8, 14681, https://doi.org/10.1038/ncomms14681.

Zeng, N., J.-H. Yoon, J. A. Marengo, A. Subramaniam, C. A. Nobre, A. Mariotti, and J. D. Neelin, 2008: Causes and impacts of the 2005 Amazon drought. Environ. Res. Lett., 3, 014002, https://doi.org/10.1088/1748-9326/3/1/014002.

Zhao, W., X. Zhao, T. Zhou, D. Wu, and B. Tang, 2017: Climatic factors driving vegetation declines in the 2005 and 2010 Amazon droughts. PLOS ONE, 12, e0175379, https://doi.org/ 10.1371/JOURNAL.PONE.0175379. 